\title{
Factors Affecting the Adoption of Peer Instruction in Computing Courses
}

\author{
Dennis Bouvier \\ Southern Illinois University \\ Edwardsville \\ Edwardsville, IL, USA \\ djb@acm.org \\ Jing Bai \\ Washtenaw Community College \\ Ann Arbor, MI, USA \\ jswanson@wccnet.edu
}

\author{
Ellie Lovellette \\ Southern Illinois University \\ Edwardsville \\ Edwardsville, IL, USA \\ elovell@siue.edu \\ Jacqueline Chetty \\ University of Kent \\ Canterbury, Kent, UK \\ J.Chetty@kent.ac.uk \\ Jia Wan \\ Randolph College \\ Lynchburg, VA, USA \\ jwan@randolphcollege.edu
}

\author{
John Matta \\ Southern Illinois University \\ Edwardsville \\ Edwardsville, IL, USA \\ jmatta@siue.edu \\ Stan Kurkovsky \\ Central Connecticut State University \\ New Britain, CT, USA \\ kurkovsky@ccsu.edu
}

\begin{abstract}
Peer Instruction (PI) as defined by Mazur, and variations on this pedagogic technique, have been in use in computing courses for about a decade. Despite dozens of educational research publications documenting positive learning effects, improved retention, student acceptance, and effectiveness for large classes; PI does not appear to be widely adopted for computing courses. This paper reports on a three-way investigation into this apparent contradiction. First, the authors reflect on their own adoption, practice, experience, and abandonment of the use of PI in computing courses. Second, we surveyed the literature regarding the use of PI in computing courses and present a summary of the research findings, variations, and extensions to PI used in computing courses. Third, a survey of computing instructors was conducted to gauge the attitude toward PI in computing courses. To add context, this report considers publications documenting usage of PI in STEM courses, and the adoption of other pedagogic techniques in computing. Particular effort was made to identify the reasons computing instructors don't adopt PI. This report also includes advice to instructors considering adopting PI in computing courses.
\end{abstract}

\section{CCS CONCEPTS}

- Social and professional topics $\rightarrow$ Computer science education.

Permission to make digital or hard copies of all or part of this work for personal or classroom use is granted without fee provided that copies are not made or distributed for profit or commercial advantage and that copies bear this notice and the full citation on the first page. Copyrights for components of this work owned by others than ACM must be honored. Abstracting with credit is permitted. To copy otherwise, or republish, to post on servers or to redistribute to lists, requires prior specific permission and/or a fee. Request permissions from permissions@acm.org.

CompEd-WGR'19, May 17-19, 2019, Chengdu, Sichuan, China

(c) 2019 Association for Computing Machinery.

\section{KEYWORDS}

Peer Instruction, education

ACM Reference Format:

Dennis Bouvier, Ellie Lovellette, John Matta, Jing Bai, Jacqueline Chetty, Stan Kurkovsky, and Jia Wan. 2019. Factors Affecting the Adoption of Peer Instruction in Computing Courses. In Proceedings of the CompEd 2019 Working Group Reports (CompEd-WGR'19), May 17-19, 2019, Chengdu, Sichuan, China. ACM, New York, NY, USA, 25 pages. https://doi.org/10.1145/3372262.3375396

\section{INTRODUCTION}

Peer Instruction (with capital letters) (PI) [23] is a pedagogic technique introduced by Eric Mazur in 1991. PI modifies the traditional lecture format by interleaving course content presentation with conceptual questions called ConcepTests [23] designed to challenge students' misconceptions. The technique encourages engagement and interactive learning from peers with immediate feedback for both the students and the instructor. The ConcepTests essentially guide the discussion, giving students opportunities to gauge and improve their understanding of the material.

Extensive research has shown PI to deliver measurable learning gains in a variety of STEM disciplines in different educational settings, and the pedagogy receives positive student attitudes and faculty perceptions [46]. PI also improves student learning in computing [42], and the technique is well received by computing students [41]. However, this approach has a very low adoption rate. This work aims to uncover some of the barriers to adoption of PI among computing instructors.

\subsection{Peer Instruction History}

In the early 1990s Eric Mazur came to doubt the effectiveness of lecturing. After attempts to explain a solution to a simple physics problem didn't result in his students' understanding, Mazur asked the students to discuss the problem with each other. He found that students are more likely to successfully grasp concepts when they 
are explained to them by their peers. This accidental discovery eventually led to the creation of Peer Instruction. Since its creation, PI has been used in a variety of STEM and non-STEM fields. Numerous discipline-based educational researchers in Physics, Geosciences, Chemistry, Calculus, and other fields have studied the use of PI, its impact on student learning, the student acceptance of PI, and the awareness and adoption of PI by faculty. Generally speaking, educational research studies report 1) improved student learning, and 2) positive student attitudes toward the use of PI. Also generally speaking, studies show more STEM faculty are aware of PI than have adopted it.

\subsection{A Definition of Peer Instruction}

To be clear, we want to make a distinction between "Peer Instruction" and "peer instruction". Mazur, somewhat unfortunately, named his approach "Peer Instruction". Though the name is appropriate, the same phrase in lowercase means 'students teaching students' in any context, while "Peer Instruction" means something much more specific. With only a difference in capitalization between the name of Mazur's technique and the general idea of peer instruction, it is difficult to find appropriate literature (e.g., some research publications use "Peer Instruction" in the title and/or keywords having nothing to do with Mazur's definition of PI), and it takes more effort to ensure that someone you are communicating with (verbally or in writing; such as in a written survey or verbal interview) understands the distinction.

Mazur's definition of Peer Instruction has evolved over time. The variations are the natural result of continuous improvement efforts. However, the basic structure of Peer Instruction remains a five-step process from the students' point of view and is outlined below.

Before Class Meeting Before each Peer Instruction class meets, students are assigned specific work to prepare them for the session. In this way, PI fits into the the broad category of 'flipped' instruction, in which students are tasked with learning foundational material on their own, reserving the class meeting for more complex topics.

- PI Student Step P-1: Preparation Students are assigned specific material to learn before coming to class. The student preparation may take different forms, such as reading or watching videos. In any form, the preparation is specific to the learning goals of the PI session to come.

- PIStudent Step P-2: Pre-class Assessment This is one place in which Mazur's definition varies. Originally, the pre-class assessment was a three question quiz on some of the most basic content. Later, Crouch and Mazur [5] suggest the preclass assessment should be an engaging learning activity with the goal of deepening the students' understanding of the material read.

Class Meeting PI class sessions typically include a cycle of 4 phases, but at the instructor's discretion may include a fifth phase, or be as short as one phase. As students are to discuss questions/topics together, the instructor may organize them into small groups at the beginning of class. It is also possible to allow students to self-organize. A class session might consist exclusively of PI session cycles, or be combined with lecture or other learning activities, again at the instructor's discretion.

- PI Student Step S-1: Question and individual vote Typically, the question posed is a single response, multiple-choice question with three or four distractors. Mazur proposed the term 'ConcepTest' for the type of question he intended: a question that challenges the understanding of a concept presented in the material. Each student makes an independent decision about the correct answer and signals that decision with a vote.

- Student Step S-2: Discuss Having individually taken a stand on the correct response, students then turn to each other to discuss the question with the goals of discussing a) why some response(s) is/are incorrect, and/or b) why some response is correct. Ideally, the group achieves a consensus on the correct response. The discussion is typically in the range of one to two minutes. The instructor (and teaching assistants if available) typically circulates in the classroom to observe and/or facilitate discussion within the groups. This discussion was once described by Beth Simon as "beautiful noise" [34].

If a sufficient percentage of students (perhaps, 90\%) have answered the Phase 1 question successfully, the instructor may choose to skip phases two to five and move on to another question.

- PI Student Step S-3: Re-vote Having discussed the question posed, students vote on the correct answer again.

- PI Student Step S-4: Redress The instructor reviews the revised vote tally and explains the correct/incorrect answers to the class as necessary.

- PI Student Step S-5 (teacher option): Isomorphic Question The instructor may ask an additional question addressing the same concept.

Steps from the instructor's point of view are listed below:

Inform Students As PI is introduced in the course, students should be made aware of what PI is, the phases, the impact it typically has on learning and course success, as well as be informed of the facets of PI activities that will affect the student's course grade.

Implementation Various activities are necessary to prepare for any PI session

- Prep prepare and assign pre-session learning (reading, video, other); prepare and perform pre-session assessment (questions, engaging activity, other); create ConcepTest questions of different difficulty levels with the specific pedagogic purpose of addressing misconceptions in the content area and fostering understanding of material and concepts.

- In class presenting material, presenting questions, gauging/collecting responses, guiding discussion, explaining solutions, and dynamically deciding on the next question depending on students' understanding of concepts.

\subsection{PI Adoption Phases}

Research on reasons educators do, or do not, adopt new teaching methodologies are provided by Hovey et al. [14] and Fossati and 


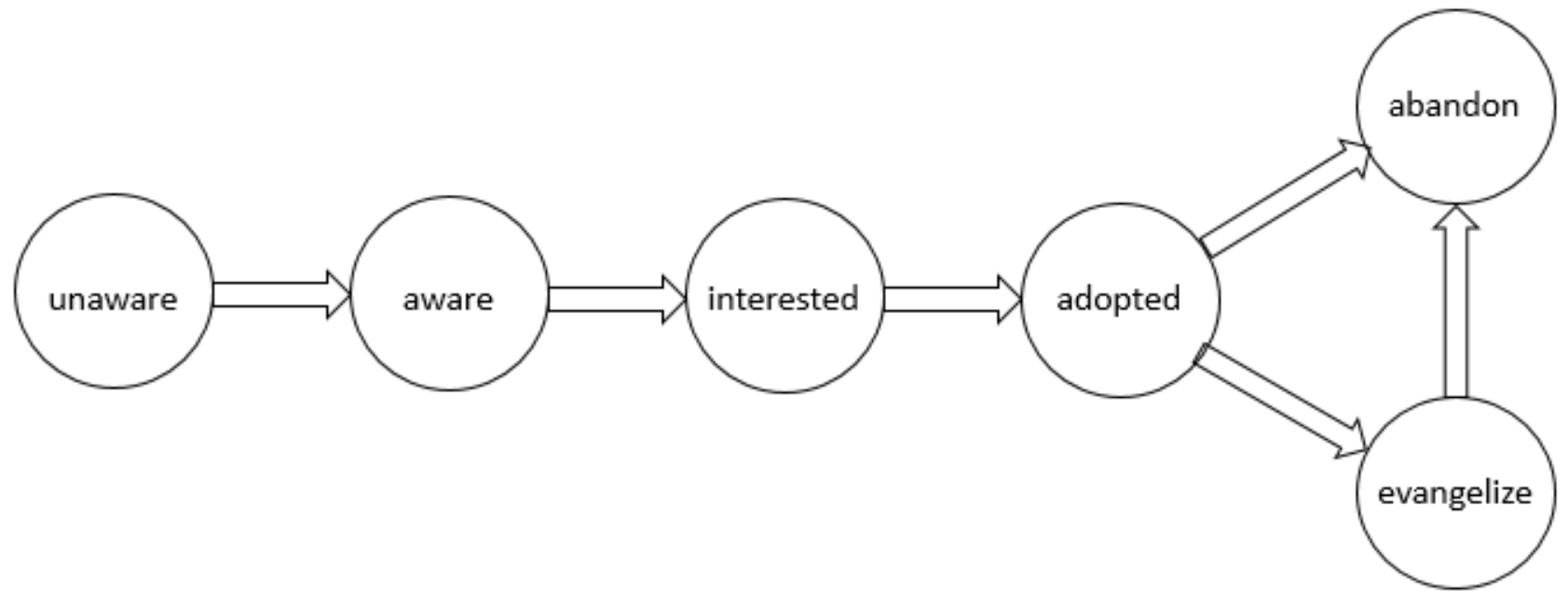

Figure 1: Evolution of instructor involvement with PI

Guzdial [11]. Rogers [35] poses a generic model of four phases of adoption of a new idea, which we use to define instructors' involvement with PI:

(1) unaware of PI

(2) aware of PI but not using it

(3) interested in using PI

(4) adopter of PI

This model is a sequence that is followed in the order presented; however, an instructor may choose not to move from one stage to the next. We extend this model to include two additional phases that follow the fourth stage:

- evangelist After having adopted PI, an instructor can make other instructors aware of PI.

- abandoner After having adopted PI, an instructor can stop using PI. An evangelist can also abandon the use of PI.

Some of the authors have transitioned through evangelist and abandoner. Figure 1 illustrates the phases and possible transitions.

\subsection{In This Paper}

This work aims to identify reasons why computing instructors don't adopt Peer Instruction. It takes a three-prong approach to accomplish this goal. Section 2 presents the authors' individual experience reports of using PI in computing courses. Section 3 presents the result of a quasi-systematic literature review of PI in computing. The computing-PI corpus is contextualized with literature from STEM disciplines. Sections 4 and 5 present a survey-based investigation of computing instructors' reasons for PI adoption and abandonment. Section 6 adds some discussion and summarizes results. Section 7 provides advice to potential adopters of PI. Finally, Section 8 provides a conclusion to the study.

\section{OUR PI STORIES}

This section summarizes the experience and evolution of each member of the working group with Peer Instruction in their own classrooms. Inspired by the conference location for the purposes of the discussion below, each working group member is identified by their Chinese zodiac sign.

\subsection{Yang (Sheep)}

Instructor Yang is from a two year community college. The school has an open door policy and its mission is to provide accessible and excellent educational programs and services. The student population is very diverse. Students come with a variety of learning abilities. Yang has taught both introduction and advanced level programming courses. Class sizes are small with 24 or fewer students.

Yang has noticed that students do better when they are actively engaged in class. The students are more open to ask questions and voice opinions when they discuss with their peers. Yang is eager to try more teaching methods to encourage in-class participation and engagement. Once they heard about PI it seemed to be a good fit.

Yang used PI in a Java based intro programming course. During class, students received some assigned reading, followed by a small demonstration. Then they were asked to read a piece of program code and answer a multiple-choice question to predict the output. This activity was implemented using PollEverywhere. After students made their choices they needed to find someone who answered the question differently and explain the reasons for their answer to each other. The group would then discuss with other groups once they came to an agreement on the answer. When everyone was done, the students were asked to answer the same question one more time. Then instructor Yang revealed the correct answer along with the explanation. Yang observed that the students showed a lot more interest in the subject when using PI. Overall, results have been positive. The percentage of correct answers was about $30 \%$ before PI and rose to approximately $90 \%$ afterwards. PI 
also helped create a sense of community within the class which has been proven to have a positive impact on student academic success.

Although the result has been positive, instructor Yang is concerned that PI could be challenging for students who need special accommodations. In addition, the particular course offered at the college is very fast paced and covers a lot of material in a short period of time. Using PI often slows down the pace of the class. Finding the right materials and questions for PI is also a challenge. There are not many available resources. The instructor is planning on using PI again in the future with some refinements like assigning reading materials prior to class and expanding the question pool.

Some of the PI questions instructor Yang uses are self-written and some are from the textbook. Yang is currently an Adopter.

\subsection{Hou (Monkey)}

Instructor Hou is from a 3 or 4 year semi-collegiate public research university which focuses on increased retention rates among minority student populations. Hou teaches introduction to programming and algorithms courses. The class sizes are big, ranging between 150 and 200 students.

Instructor Hou's original major was computer security. As they became aware of the importance of higher education pedagogies, they made the decision to shift their focus to CS education. Hou is passionate about teaching programming, and since the topic is challenging by nature, the instructor has always tried to make use of a variety of pedagogical approaches to engage students. When they came across the PI methodology during their $\mathrm{PhD}$ research, instructor Hou realized that their teaching approach fits into the PI definition.

Each PI class is conducted in 2 phases. The students answer the question, discuss with other students, then answer the same question again. It assists students with meta-cognitive skills as well as allows instructor Hou to gauge students' knowledge. PI is also used in a flipped classroom to assist with knowledge retention. The instructor originally used a show of hands, pen, paper and white boards and then progressed to using Socrative.

Hou has been very pleased with the positive feedback. The sections that were using PI had higher success rates compared to non-PI sections taught by other instructors.

Instructor Hou's biggest concerns are the lack of certainty that PI is a good fit for some of the topics covered in the course and the accuracy of question/answer sets used. Preparation for PI classes can also be very time consuming.

All of the PI questions instructor Hou uses are self-written. Hou is currently an Evangelist.

\subsection{Long (Dragon)}

Instructor Long is from a large public university with a focus on undergraduate teaching with research. Long teaches the introduction to programming course to students in computer science and other majors. The class is medium-sized with around 40 students.

PI was introduced to Long by one of their colleagues. Long observed the class taught using Peer Instruction. The class size was a lot larger than theirs. They were very impressed by how engaged the students were in learning.
Long tried PI in their own intro to programming class and found it rewarding to have an active classroom. Students asked meaningful questions and the success rate increased. In informal surveys students also reported positive attitude toward using PI with the exception of the time limit on clicker-based reading quizzes.

The Peer Instruction practice was continued in the intro to programming courses taught by Long in following semesters. In each attempt it was difficult for Long to find the time to keep it going as the semester progressed. Creating good questions, finding the right reading assignments and recording participation data took a lot more time than anticipated. The materials used previously also needed constant updating due to changes in textbooks, technology for response systems, and errors found in previous work. In addition, it was challenging for instructor Long to find the right technology to support PI practice. The software being used had limitations and the university changed its response system.

The attempt at spreading PI to other intro to programming instructors has not been successful as most of them felt the current teaching methods used were sufficient.

All of the PI questions instructor Long uses are self-written. At the time this paper was written Long was an Abandoner but currently the instructor is an Evangelist.

\section{$2.4 \quad \mathrm{Niu}(\mathrm{Ox})$}

Instructor Niu works at a large public university and teaches mainly upper-level undergraduate and graduate courses in software engineering. Niu's university prides itself on small class sizes, which translates into 20-25 students.

PI has been at the perimeter of Niu's awareness for a considerable amount of time. However, instructor Niu has always been under the impression that it worked better in courses where one could come up with ConcepTests that would have "concrete answers", such as the value of a variable or the output printed to the screen. Since most of Niu's courses were in software engineering, PI did not seem like a natural fit. Finally, an opportunity arose when Niu taught a senior design course. The coursework includes a number of readings followed by in-class group discussion sessions covering topics such as professionalism, ethics, legal issues, and lifelong learning among others.

Elements of PI were incorporated into the discussion sessions, each of which typically took up an entire class meeting. Every discussion session focused on a single topic and included required readings, typically taken from current issues of IEEE Software and other trade publications. Two pairs of students lead each discussion session, where one pair presented and defended the points raised in the article, and the other pair argued against. With PI, these discussions were preceded by a ConcepTest question with 4-6 answers, most of which were ambiguous or arguable. Students in the class voted using the web-based polling system PollEverywhere. The answers were shown to the entire class; however, the correct answer was not revealed right away. Working in teams of four or five, all students were asked to come to a consensus within the team, identify a single best answer, and then briefly present it to the entire class. Then, the discussion based on the readings followed with the aim to find a common class-wide decision. 
Instructor Niu experienced a number of challenges. No PI resources were available for software engineering or related topics, which necessitated the creation of new ConcepTests. Having read relevant educational research literature, but lacking prior experience with PI, Niu was concerned about the quality of ConcepTest they created. Although some of these doubts were unfounded, the instructor found out that some questions did not include answers that students would have selected as a result of final discussions. Most importantly, Niu realized that their original concerns about software engineering not being the best fit for Peer Instruction became even stronger. Student engagement and participation was already strong in this course and the introduction of PI did not lead to increasing it further. PI was used in twelve out of fifteen discussion sessions during the semester. Presently, instructor Niu is planning to refine the currently created ConcepTests and use them the next time this course is offered.

All of the PI questions instructor Niu uses are self-written. Niu is currently an Adopter.

\subsection{Gou (Dog)}

Instructor Gou works at a large public university. Classes taught by Gou are in the medium range with about 40-64 students.

When instructor Gou was at the very beginning of their teaching career, a senior colleague recommended PI as a viable teaching methodology for a Java-based CS1 course. Instructor Gou decided to follow that advice. Students in this course received electronic clickers with their textbook. Instructor Gou developed an extensive set of slides supplemented by multiple ConcepTests for each topic. Each one presented exercise questions covering relevant topics: some of them were regular examples, some of them were edge cases and trick questions designed to make students pay attention and think. Students had about a minute or two, depending on the question, to answer individually. Once the answers were revealed, instructor Gou moved on if the students had $100 \%$ accuracy. If the answers were strongly skewed towards the right answer with just a few stragglers, instructor Gou would ask a student to explain why something was not the right answer. If there was a split, instructor Gou would let students discuss each answer option and vote again. Additional test review sessions were composed entirely with ConcepTest-style questions.

Students in instructor Gou's classes consistently and overwhelmingly reported that they enjoyed the elements of PI in their course evaluations. Gou also found that students were much more engaged and invested in the class compared to other classes where PI was not used. Ultimately however, Gou was forced to abandon PI after five semesters because the contract with the company providing the clickers ended, and the committee formed to choose a replacement never produced a viable decision on how to proceed. Consequently, Gou continued teaching the same course without using PI.

Most of the PI questions instructor Gou used were self-written, the rest were from another PI evangelist faculty member. Gou is currently an Abandoner.

\subsection{Zhu (Pig)}

Instructor Zhu works at a small private college and teaches small classes including introductory courses of up to 20 students.
Instructor Zhu learned about Peer Instruction being used in some Physics courses at their college. Students were very opinionated about it: some liked it and some hated it. At some point, based on student feedback about spending less time on concepts and more time on hands-on programming, instructor Zhu asked their Physics colleagues about best practices to incorporate PI into their coursework. A concern still remained about how to find the right amount of necessary theoretical foundations to balance practical aspects that students wanted and how to avoid trading those "basics" for "programming only" class time, as some students demanded. Hiring an assistant to lead programming labs was not an option at their college.

PI offered a viable solution for flipping the classroom in Programming I and II courses taught by instructor Zhu. They pre-assigned reading material for each class and created corresponding quizzes. Every class began with a ConcepTest-style quiz, followed by student discussions with peers. This usually took about half of the class time. Instructor Zhu found that in the second half of the class, no matter whether the focus was on hands-on programming or conceptual discussion, the students paid more attention compared to this instructor's classes without PI. Zhu only tried PI in their most recent semester, and there is still a lot to explore and improve for the future. For example, Peer Instruction can also be combined with pair programming, which is something that this instructor will explore in the near future. Zhu is concerned that not all students complete reading assignments and that ConceptTest-style quizzes at the beginning of every class do not always provide enough motivation to complete the readings.

Some of the PI questions instructor Zhu uses are self-written and some are from textbook quizzes. Zhu is currently an Adopter.

\subsection{Tu (Rabbit)}

Instructor $\mathrm{Tu}$ is a teacher at a large public university. When beginning with PI, the Computer Science department was just starting a period of explosive growth, and it was thought that this approach would be useful in making the transition from smaller to larger classes. In this case, the first class taught had 23 students, and the final largest class had 53.

The department was supportive of using PI, and the department chair provided slides with ConcepTests and other relevant materials. Instructor Tu used PI in several sections of CS 1, and often experienced good results. In the beginning, the use of clickers seemed silly in a small class as Tu did not understand why the same questions couldn't just be discussed in class. Instructor Tu reflects that they sometimes felt more like a game show host than a teacher while waiting for students to click in. Tu was left unsatisfied by the "gotcha" nature of many questions and the general lack of nuance in teaching using multiple choice questions.

Reflecting on Peer Instruction, instructor Tu was most satisfied with the high level of student involvement, although it wasn't clear that students were learning the right things. Interestingly, in student evaluations, the most mentioned part of the class was coding examples. For students learning to program, it seemed that examples of programming were more useful (and engaging, for unknown reasons) than discussing the answers to multiple choice questions. 
Following discontinuation of the technology used to collect student answers in PI, instructor Tu had to rework all of their teaching materials. The coursework was changed to include more direct coding; in-class exercises were discussed in the same fashion as ConcepTests but accommodating more diverse answers.

Instructor Tu also tried to use PI in a discrete mathematics class. Unfortunately, it was taught in a room with poor acoustics where the chairs could not be moved. Students had a very difficult time communicating with each other as they were basically forced to scream across a row of desks. This also made the discussion uncomfortably loud, which resulted in complaints from adjoining classrooms.

Ultimately, instructor Tu switched to teaching Software Engineering and couldn't find a meaningful way to successfully incorporate PI into this type of course.

Some of the PI questions instructor Tu used were self-written and some were from another PI evangelist faculty member. Tu is currently an Abandoner.

\subsection{Summary of our own experiences}

There was a range of overlapping objectives that the members of this working group sought to achieve by adopting PI in our courses:

- To engage students in everyday coursework in many types of courses across many subjects in classes ranging from very small to a couple of hundred students,

- To increase student engagement in a very diverse population with different levels of academic readiness in an introductory programming course,

- To improve retention of underrepresented students in large introductory programming classes.

All of the working group members achieved increased levels of student engagement in their classroom, as expected. For many of us, as a result of using PI, levels of student attainment of course learning outcomes have also increased. Furthermore, many of us noticed that it helped students create a sense of community, which is another proven practice for improving student success and increasing student retention levels.

Members of this working group identified a number of concerns based on our individual experiences with PI:

- All members of this working group are concerned about being able to develop a good set of questions and answers for ConcepTests that accurately reflect the course material, primarily due to lack of existing Peer Instruction resources. Creating new ConcepTests is a significant time commitment. Developed ConcepTests would typically require ongoing maintenance to adapt to updated or new textbooks and readings, as well as changing technology.

- PI does not appear to be working well for some students with special needs who may require additional accommodations.

- Many computer science courses, especially introductory courses such as CS1, are very fast-paced. A significant amount of material needs to be covered within a relatively short time. Some of us are concerned about finding the right balance between Peer Instruction and other classroom practices.

- Several members of this working group are not sure whether PI is a good fit for certain courses, such as algorithms and software engineering. Topics in these courses do not naturally translate into ConcepTests that have a finite number of clearly-defined short answers. Open-ended discussions are usually a better fit for material covered in these types of courses.

- It was difficult for some of us to find the right technology to support Peer Instruction. Some institutions require students to purchase clickers, which could make the adoption of peer instruction easier. However, this creates an additional student expense and increases the likelihood that students can forget, lose, or break their clickers. Some of us decided to stop using PI when the institution stopped providing or requiring students to acquire textbooks bundled with clickers.

- PI has been shown as an effective methodology for flipping the classroom when students are required to complete assigned readings prior to class. Some of us found that a number of students ignore that and still come to class unprepared leading to many difficulties with participating in classroom activities.

- Some classrooms may not have the physical layout conducive to conducting discussions in small groups. Students should be able to easily form clusters and communicate with each other without creating distractions for themselves and others.

\subsection{Motivation}

Our own experiences, both positive and negative, motivated us to seek out the literature on PI in computing for experience reports and research results, and for any insight or guidance into successfully deploying PI in a computing course.

\section{LITERATURE REVIEW}

The authors were familiar with publications on PI in computing; however, a search found no summary of the publications on "PI in CS". Thus, we performed a quasi-systematic review of the available research.

\subsection{Literature Review Methodology}

This review of literature on PI in computing was informed by the guidelines proposed for systematic literature reviews by Kitchenham and Charters [18]. These guidelines were also cited by recent large scale reviews of the literature on introductory programming $[22,24]$.

Our literature search deviated from the guidelines in that we did not validate the quality of the search result. However, given the low chance of a digital library excluding a relevant item with "peer instruction" in the search string, there seemed very little point in evaluating the result. Additionally, the literature review presented here is only a component of this research study and report.

The process we followed included these steps:

(1) define literature review Research Questions

(2) search digital libraries

- search the ACM Digital Library with this search string: "peer instruction" 
- perform a Scopus document search with this search string: "peer instruction" AND ("computing" OR "computer science” OR “programming”)

(3) remove duplicates that appeared in the combined results

(4) manually exclude bad hits

- an item was excluded if it was less than four pages in length, was an abstract only (e.g., a description of a workshop, panel, or other presentation), or was a listing of proceeding contents

- an item was excluded if it was not based on the "Peer Instruction" technique defined by Mazur.

(5) analyze the remaining items

- classify the items in groups

- compute descriptive statistics

3.1.1 Literature Review Research Questions. The Research Questions (RQs) motivating the search:

(1) In which computing courses has PI been used?

(2) What effect does PI have on teaching computing courses?

(3) What factors in the adoption of PI are reported?

3.1.2 Literature Review Search Results. The literature search commenced in May 2019. The first search of documents was only in the ACM Digital Library. After getting a sense of the size and scope of the contents of the ACM DL, the search was expanded to include Scopus. A new search was performed on the ACM DL on 10Jun19. On the same date, the Scopus search was done. The combined searches identified 196 documents. 49 documents remained after removing duplicates, reprints, and off-topic documents. The vast majority $(90 \%, 44$ of 49$)$ of these documents are available in the ACM Digital Library.

PI first appears in computing literature in 2000. Naturally, an increasing number of papers have been published each year since the first paper in 2000. Perhaps this is an indication that PI in CS is becoming increasingly popular [4, 29, 51, 52].

The corpus identified by our search was written by 149 authors. The largest number of authors on a single paper is 8 . It is remarkable that approximately half ( 25 of 49 ) of the papers are authored, or co-authored by Leo Porter, and an even larger portion of the papers are authored by people affiliated with the University of California San Diego.

All 49 documents were read, and documents relevant to specific RQs were tagged for easier analysis. The initial tagging was conducted by one Working Group member. A sub-group of the working group was formed to undertake literature review. This group, which did not include the person who did the original tagging, reviewed and revised tags via discussion and consensus.

Additional themes in the corpus emerged as we tagged the documents relevant to specific RQs. The resulting set of themes are listed below. Many documents were tagged with multiple tags, thus the counts do not sum to 49 .

- experience reports (RQ1) 26 documents reported on an experience using PI in a specific context or course without empirical evidence

- student attitude (RQ2) 15 documents reported on students' attitudes toward using PI
- learning (RQ2) 16 documents reported on the impact on student learning in using PI

- adoption (RQ3) 1 document reported on issues related to adoption of PI

- empirical 31 documents reported quantitative evidence for results reported

- technique 12 documents reported on variations and/or details in the technique of using PI

- beyond 11 documents reported on extensions to using PI, such as using PI data to identify students who may not succeed

3.1.3 Literature Review Search Results. The following subsections summarize some of the themes found in the corpus. In particular, we include the themes corresponding to the RQs. In some subsections, we include documents not identified by the search. This is particularly true in the theme of adoption in which a number of relevant studies were included that were either not computing specific or not PI specific.

\subsection{Literature: computing courses (RQ1)}

The literature search identified a number of publications that report on the use of Peer Instruction in a wide-variety of computing courses. These courses include CS0, CS1, CS2; and a variety of upper-division courses such cybersecurity and computing forensics.

3.2.1 PI in CSO. Spacco et al. [42] studied PI in the context of CS0 to determine the extent to which how a class is taught determines what is learned. The study compared two sections, taught in the same term by the same instructor, one with traditional techniques and the other with PI. Porter et al. [27] examined the use of PI in a CS0 course as part of a broader discussion of its use in four different courses. Simon and Cutts [38] discussed how to implement a PI-designed CS principles course.

3.2.2 PI in CS1. Although PI can, and has, been used in a variety of CS courses, the majority of PI studies are focused on CS1 courses $[3,32,33,48]$. Of the papers analyzed in this study $37 \%$ focus on the implementation of PI within CS1. The prominent institutions adopting PI in CS1 courses include the University of California (UCSD) $[28,39]$, the University of Toronto [53] and Stanford University [20], with the majority of research regarding PI stemming from these intuitions. There is a small European influence from universities such as the University of Glasgow [6]. The body of research on PI in CS1 stems from the same primary authors - Porter, Zingaro, Simon, Lee, and Cutts. They have adopted the standard way in which PI is implemented where students individually answer a posed question using clickers (or another technological tool), discuss with peers, and then re-evaluate their answer and individually make use of a clicker to answer the question for a second time.

3.2.3 PI in upper-CS. The development of PI questions for use in a digital forensics workshop was described extensively in $[15,16]$, and an analysis of question types reveals that qualitative example and scenario based questions are most suitable. The use of PI in a cybersecurity course is described in [7]. Peer Instruction questions 
have been used to gauge student learning in an operating systems course [47].

An interesting study on the use of PI in a software engineering course [9] described adjustments that were made to accommodate the ambiguous nature of questions in software engineering. Since considering different answers is an important part of the analysis process, a modification was made such that students were able to suggest answer options. The resulting discussions allowed students to debate tradeoffs between different plausible solutions. The paper posited that PI could be used successfully even in situations where there was possibly more than one correct answer.

The successful use of Peer Instruction in Theory of Computation and Computer Architecture courses was documented in [26, 47].

\subsection{Literature: Student Attitudes (RQ2)}

An important barrier to instructors' continued use of evidencebased instructional pedagogy is the resistance of students to instructional pedagogy that differs from the way they expect a course to be taught [10]. This indicates that students' positive reception of new teaching methods is crucial for their adoption and continued utilization.

It has been established that students may require a period of adjustment when a new pedagogical tool is introduced into the classroom [23]. It is therefore not uncommon for students to be discouraged initially or to complain about why a course is being taught in this way. Crouch and Mazur [5] found that after a period of adjustment the majority of students appreciated the interactive approach of the course, and their appreciation was reflected in the course evaluations. Simon at al. [40] found that although initially students were skeptical of PI, they acknowledged that they learned from discussing concepts with others. The latter study also analyzed students' attitudes towards PI and found the following:

- Students felt that PI provided a comfortable learning environment where they could discuss concepts freely without feeling embarrassed;

- Students found classes to be fun, not boring and they enjoyed discussing concepts and participating in the learning process;

- Students felt a sense of responsibility towards other students in the class and sensed that whether or not pre-class reading was completed affected not only themselves but the entire group;

- Students expressed being more confident conveying their thoughts to others as they had an opportunity to express themselves and practice sharing their opinions with their peers. This led them to be more confident to ask questions in larger groups;

- Students felt that being part of a group provided them with an opportunity to make friends, not just during class - it let them feel less isolated and they were able to study in groups;

- Students said that PI lectures helped them comprehend topics with a deeper understanding instead of merely memorizing facts;

- Students indicated that PI promoted critical thinking as they were encouraged to develop their reasoning skills;
- Discussions during the PI process also assisted students with understanding why their answers were incorrect along with why the correct answer was right;

- Students felt that the feedback they received immediately was valuable for their learning;

- Students found that the topics were easier to learn within a PI setting.

The same study also noted that some students felt that PI created a fake environment where they were expected to be answering quizzes and not caring about the learning.

An investigation by Porter et al. [31] was conducted in a small liberal arts college that adopted a PI approach to teaching in a CS course. In an attitudinal survey, students stated that the clickers were useful for "staying awake in class", and for coming away from class feeling "awake, energized and awesome..." The study recommended that, to attain student buy-in, it was important for students to recognize that they were not being evaluated based on their answers to clicker questions. The researchers also noted that teacher involvement could be useful, especially if it helped groups focus correctly on the questions.

Peng [25] reported on a PI approach to teaching Java within a small department. Students responded that PI helped them recognize what was difficult in the reading and that pre-reading helped them identify difficult concepts and material. Students' attitudinal responses according to a survey conducted revealed that solo voting provided them with an opportunity to attempt an answer before speaking to other students, with immediate feedback so that they could focus on their weaknesses. The group discussion helped them better understand the material, and they felt that it was valuable to their learning. Students felt that they came away from PI lectures being able to stay awake, energized and feeling pleased that they knew the content.

Kinne et al. [17] studied the efficacy of PI and found that most students find value in it. The survey conducted in [30] was used to determine students' attitudes towards the instructional method. Of the 12 questions posed to students, 8 questions achieved an $80 \%$ or more agreement rate. For example, students felt that thinking about a question on their own before discussing it was helpful in learning course material; the immediate feedback received from answering the question provided them with an understanding of their weaknesses; it was valuable to discuss questions; and students felt that by the time they had discussed and re-voted they were very clear about what the answer should be. Interestingly, there were more students that agreed with this statement than any other. Overall, students had a very positive outlook on PI after experiencing lectures in this way.

Zingaro [48] asked students enrolled in a CS1 course with PI and a traditional CS1 course to rate their self-confidence on a variety of programming tasks both at the beginning and and the end of the semester. The students in the PI section exhibited statistically significant gains in self-efficacy compared to students in the traditional lecture section.

Lee [20] studied students taking a CS1 course that made use of PI and found that student approval rose from $73 \%$ before PI was employed to $81 \%$ the first time it was offered to $88 \%$ at the second offering. 
Porter et al. [28] conducted a study aimed at upper-division computing courses (computer architecture, theory of computation) and also found that between $85-89 \%$ of students said they benefited from peer discussion. Students felt that PI was valuable to their learning and that the peer discussion caused them to learn more during the lecture. Students expressed that learning about different answers related to a question provided them with an opportunity to think about answers from different perspectives.

Overall, we found 14 papers in the ACM digital library that reported positive student attitudes towards PI in computing courses. This is the overwhelming sentiment from studies of student attitudes in other STEM disciplines [46].

\subsection{Literature: Measuring Student Learning (RQ2)}

It is plausible to assume that instructors would be willing to adopt a new pedagogy if research shows learning gains and decreased dropout rates resulting from it.

Porter et al. [31] studied student learning with PI at small liberal arts colleges. They addressed skepticism that PI techniques worked well only at large research-oriented institutions by studying 11 different classes offered at smaller colleges. In all 11 classes, all types of questions showed a normalized gain (gain between the initial individual responses and the ultimate group vote) between $29 \%$ and $41 \%$. The greatest gains were reported when teachers participated in student discussions as opposed to just observing. This would seem to be an obvious addition to the PI methodology, and the researchers stated that "This involvement can still be viewed as being within the intent of the PI process."

Porter and Simon [32] studied the effect of PI (as well as Media Computation and Pair Programming) on retention. They found a non-significant increase in retention among females, but males' retention rate improved from $60 \%$ to $82 \%$. The reasons given were that best practices provide context to programming tasks, increase student interest and engagement, and foster community between students.

Deshpande et al. [7] showed that PI improved the dropout rate by $4 \%$ over two non-PI control classes. A substantial decrease in the CS1 dropout rate when PI was employed was also found by Lee in [20].

Porter et al. [26] found that PI reduced failure rates from $20 \%$ to $7 \%$ overall. This change was not due to "better" instructors adopting PI, as for same instructor results, changing to PI reduced failure rates from $23 \%$ to $8 \%$.

Simon et al. [42] showed that PI students scored $5.7 \%$ higher on the final exam, with improvement across all groups, including males and females, and upper and lower division students.

Deshpande et al. [7] found that PI improved the failure rate by $13 \%$ on quizzes and 3\% on exams. Zingaro and Porter [49] showed that PI improved performance on the final exam.

Greer et al. [12] studied student performance using both traditional lecture format vs. PI, and the location of the instruction (lecture hall vs. active learning classroom), and found that while the methodology was important, the location was not. This implies that PI can be successfully implemented with corresponding benefits to students in a variety of classroom settings.
Porter et al. [28] use isomorphic, or similar, questions to determine "whether the group discussion resulted in generalizable learning." Across a sample spanning four courses, in all cases there was an improved correctness rate on a second isomorphic question after a discussion. They also found that questions considered isomorphic by professors are not necessarily experienced that way by students, and they introduced a new metric by which to rate the isomorphism of different questions.

Altogether, this study found $15 \mathrm{ACM}$ publications that reported improved student learning as a result of PI. Peer Instruction has been shown to have a positive impact on student learning in a variety of STEM disciplines across different institutions [46] by promoting students' conceptual understanding, enhancing qualitative and quantitative problem-solving skills and reducing attrition rates.

\subsection{Literature: PI Technique}

It cannot be discounted that depending on the context in which PI is applied, individual instructors will have preferences and will want to introduce changes and try different things in the hope of making improvements to the process. However, when implementing PI, it is important to follow the major steps in the Mazur framework and to contemplate the effect modifications on the PI cycle may have on both student and instructor experiences and learning outcomes.

Turpen et al. studied Peer Instruction in the context of physics faculty [44]. The researchers focused on teaching practices in introductory physics courses, with results based on interviews with 15 individual instructors who used PI methods. It was found that there are variations on PI, with changes often implemented according to individual preferences or circumstances. The two most often modified features were found to be the use of multiple choice questions and vote after discussion, both of which were changed by at least half of respondents. The use of multiple choice questions was altered as many faculty considered "class exercise" worksheet activities to be Peer Instruction. The vote was often substituted with an informal discussion, or the teacher walking around the class to gauge the extent of student knowledge. The study further reports two common difficulties with implementing PI. First is the difficulty of getting students to participate and talk with other students. Possible solutions include listening to, engaging and joking with students. A second problem is finding good PI questions, with the result that many teachers pulled questions from sources such as textbooks and magazines.

A detailed study [46] of PI across STEM disciplines including computing posits that the successful implementation of PI often disqualifies major modifications to the original Mazur model. The researchers found that challenging ConcepTest questions addressing misconceptions in a specific area deliver the most learning gains. Basic recall questions or easy questions have limited benefits. Additionally, time for the students to ponder the question by themselves and the first individual vote are important and should not be skipped as they improve the student learning experience. When electronic response devices are used (although PI can be implemented without them), the instructor views the results and determines how to proceed. However, when shown to students the results of the individual vote have been found to bias the discussion 
and re-vote. Crouch and Mazur [5] found that peer discussion resulted in substantial learning gains when the proportion of correct responses from the individual vote was even as high as $70 \%$. Correct response below $35 \%$ merits extra hints and peer discussion delivers marginal returns [41] and when accuracy is over $70 \%$ the instructor should skip the discussion and explain the answer. Porter et al. [28] found that peer discussion resulted in improved learning gains for $13-20 \%$ of students in upper-division CS classes. Research from the field of physics [19] posits that the learning gains shown by the re-vote accuracy rate are due to peer discussion and not a result of other metacognitive processes. Even though the body of research of PI in STEM fields indicates that its value may be overstated by the difference in correct answer rate between the initial vote and re-vote, peer discussion nevertheless positively impacts learning [46]. Lastly, the explanations given by the instructor at the end of the ConcepTest question also influence how effective PI is for student learning. Zingaro and Porter [50] conducted an experiment with isomorphic questions in CS1 and learned that peer discussion coupled with instructor explanation is superior to peer discussion alone. In a followup study [49] that combination translated into improved final exam performance.

As a side note, research from the field of Astronomy suggests that if instructors elect to award points for answers recorded with digital response devices, the introduction of conversation bias during the peer discussion portion may be avoided if the points are awarded for participation rather than for accuracy [46].

All of this suggests that it's important to carefully consider major changes in the PI cycle and how they may affect student learning and experiences. An unsuccessful implementation of an overly modified PI methodology may lead to abandonment and propagating negative opinions to other instructors.

\subsection{Literature: Adoption (RQ3)}

A body of research from Arts and STEM disciplines [1, 2, 21, 36, 43] keeps arriving at the same conclusions - one of the most significant barriers of the implementation of teaching innovation named by faculty is the lack of time. The research also points to the lack of training and incentives or rewards as major hurdles. Another issue is the focus on research over teaching either because instructors consider themselves scientists first or because their professional advancement depends on producing research, or because their institutions, peers or the faculty themselves do not value teaching as much as they value scientific endeavor. Some instructors don't even have a choice in the matter, as they don't have control over curriculum or courses they teach or how they are developed, nor do they influence class sizes, classroom setup, or the availability of required technology. Other important non-environment but personal issues that may prevent faculty from trying new teaching methodology include their own pedagogic beliefs and perceptions, their awareness, knowledge and skills.

In [35] Rogers describes the process of adoption of a new idea as occurring in five potentially overlapping steps: knowledge, persuasion about benefits, a decision to use the innovation, implementation, and confirmation of continued use. These steps are crucial to understanding the processes behind the adoption of Peer Instruction. Instructors learn about Peer Instruction (and other pedagogies) from various sources, including their peers, workshops, published research literature, Internet sources, and professional conferences. These sources, along with personal characteristics and internal concerns, may also influence their decision whether or not to proceed to implementation or to continue or abandon use.

In a study of physics faculty Henderson et al. [13] found that $12 \%$ of the surveyed instructors lacked any awareness on researchbased instructional strategies, including PI, $18 \%$ of the faculty aware never tried implementing any innovation, and a third of the faculty who did use new instructional strategies abandoned them. The researchers found that reading journals and attending workshops were correlated with both the awareness of teaching innovation and the decision to try out new methods. What influenced the confirmation of continuous use however was the faculty's own interest in using more innovative strategies as well as being female. Reasons for abandonment of research-based instructional strategies were complaints from students, weaker learning gains than promised, and inability to cover the expected amount of material. Another reason for abandonment was not following the pedagogy but modifying it without the proper knowledge or awareness of potential consequences.

Results from some important studies on reasons for or against the adoption of PI are outlined below.

Hovey et al. [14] studied why CS faculty adopt new teaching practices of any type, finding that concern for students' learning as well as consideration of logistical issues influenced adoption. Potential challenges in incorporating new teaching techniques were concerns about adverse effects on tenure (students might give bad evaluations and other professors might be skeptical), as well as being uncertain about techniques that they themselves had not experienced when they were students. Reasons for trying included concern about students' understanding, engagement and performance. Reasons not to try included lack of time, resources, and understanding of logistics as well as being content with current methods.

These findings are echoed in a study by Eickholt [8] in which Midwestern CS faculty and administrators and support staff were surveyed and asked about the most common barriers to implementing evidence-based active learning teaching practices, including PI. Both faculty and administrators pointed to time as the most significant hurdle. Faculty then listed class size as being the second most prohibitive reason followed by no incentives, no need to innovate, lack of institutional support and lacking technology. Administrators and support staff on the other hand thought that the second biggest barrier was the lack of faculty motivation, followed by teaching innovation not being valued by their institution, faculty being unaware of pedagogy and last, the lack of active learning spaces.

Porter et al. [26] evaluated 10 years of instruction of 4 courses in CS where PI had been adopted as a methodology within the classroom. The primary benefit was that the failure rate was halved. The study is of significance as it reports failure rates of non PI classes and PI classes over a 10-year period within a specific course.

In another paper Turpen et al. [45] interviewed 35 physics faculty. The top reasons for aligning with Peer Instruction were: first, many instructors were already convinced of the value of the new technique over general instruction, and of the shortcomings of 
the lecture format. Second, Peer Instruction was chosen because it is relatively easy to implement and integrate within lectures. Encouragement from their department for PI and other academic innovations was also important.

Crouch and Mazur [5] found that instructors adopt PI so that students are encouraged to do pre-class reading and are more prepared for class.

Porter et al. [27] report that the adoption of PI within CS is low. The authors conducted a multi-classroom study across multiple instructors, institutions and computing courses to report why these instructors adopted PI. The benefits of instructors adopting PI relate to first, instructors being able to adapt the class so that students misunderstandings are addressed. Research shows that students often have misconceptions related to programming concepts, especially when students do not have experience with programming. PI provides a way to identify and correct these misconceptions. Second, students often foster a deeper understanding of CS concepts as they engage with what is being taught. Third, communication and teamwork is greatly enhanced as small group discussion and class-wide analysis takes place during PI. Finally, the ease at which PI is implemented does not require any changes to the seating arrangement within a classroom.

Hovey et al. [14] collected survey responses from 821 CS faculty at 595 institutions in the U.S.A. to investigate why computing instructors adopt or do not adopt new teaching practices. Reasons for not adopting a new teaching practice include feelings of being overwhelmed, not having enough time, and worries that use of a new practice would take a lot of class time and artificially limit the number of topics that could be covered. Also implementation difficulties were encountered. Other concerns are lack of resources, lack of an appropriate room (for example, teaching in a large theatre with immobile chairs makes group participation difficult), and a need to change course structures to accommodate the new teaching practice.

\subsection{Literature Review Summary}

The aim of the Literature Review was to focus only on PI within CS, and to answer research questions related to the types of courses that instructors adopted PI for, the effects of PI, and the varying factors of why instructors adopted or found barriers to adopting PI. The literature found for PI in CS was reduced to 49 documents, identified by tags such as attitude, adoption, barriers, and so on.

The literature found that students taking PI courses adapted well for a variety of reasons, from the benefits of collaborative learning to the notion of being able to think critically within a comfortable, non-threatening environment. Not only were students' attitudes positive, but the learning as well as the pass rate improved for courses that adopted PI. There were a variety of reasons why instructors adopted PI or found barriers not to adopt PI. These ranged from high workloads to doubts about PI's success. The overwhelming benefit of PI was the improved pass rate.

\section{SURVEY}

A survey containing 33 questions was created in Qualtrics and distributed to computing instructors. Survey participants received partially disjoint subsets of questions depending on their reported familiarity with Peer Instruction. Responses were anonymous. The survey is included in Appendix A. Multi-answer options are marked with $\square$, single answer options are marked with $O$.

\subsection{Pool and Distribution}

The survey was disseminated in the spring of 2019. It was sent to the SIGCSE (Special Interest Group on Computer Science Education) member list of about 1000 via anonymous link. It was also distributed via invitation to a list of 4065 emails synthesized by Chris Hovey [14]. The list was a sample of faculty members teaching lower division introductory courses in computer science at 1,310 institutions representing all institutional types per IPEDS (U.S. Department of Education Integrated Postsecondary Education Database System) definition awarding Baccalaureate and Associate's degrees in 2014 and 2015 [14]. The survey was successfully delivered to 3890 valid email addresses with two reminders to nonrespondents 3 and 7 days after the initial mailing. 125 completed anonymous responses were recorded by the end of day 12 after the survey went live.

\subsection{Respondent Characteristics}

Due to the nature of the mailing lists used to disseminate the survey, the 125 respondents were predominantly (95\%) from North America. 3 faculty in Australasia, 2 in Asia, and 1 in Europe also completed the survey.

The breakdown of respondents by institution type and size can be seen in Tables 1 and 2 .

\begin{tabular}{|l|c|}
\hline Institution Type & Count \\
\hline 2-year undergraduate & 15 \\
\hline 4-year undergraduate & 37 \\
\hline Undergraduate and Master-level & 25 \\
\hline Undergraduate and post-graduate & 47 \\
\hline Other (both 2- and 4-year programs) & 1 \\
\hline Total & $\mathbf{1 2 5}$ \\
\hline
\end{tabular}

Table 1: Breakdown of respondents' institution type

\begin{tabular}{|l|c|}
\hline Institution Size & Count \\
\hline Very Large (>20,000 students) & 32 \\
\hline Large (12,001-20,000 students) & 18 \\
\hline Medium (6,001-12,000 students) & 30 \\
\hline Small (3,000-6,000 students) & 18 \\
\hline Very Small (<3,000 students) & 27 \\
\hline Total & $\mathbf{1 2 5}$ \\
\hline
\end{tabular}

Table 2: Breakdown of respondents' institution size

Survey participants were also asked about their personal rank, tenure status and teaching experience. Of the 125 respondents, 76 indicated having tenure, 23 said they were not tenured or were on a tenure track, and the remaining 26 were in non-tenure track positions. Table 3 shows respondents' teaching experience vs. rank. 


\begin{tabular}{|l|c|c|c|c|}
\hline Years of Experience & $\begin{array}{c}\text { Early } \\
\text { Rank }\end{array}$ & $\begin{array}{c}\text { Mid } \\
\text { Rank }\end{array}$ & $\begin{array}{c}\text { Senior } \\
\text { Rank }\end{array}$ & Total \\
\hline 0 to 5 years & 7 & 2 & 2 & 11 \\
\hline 5 to 10 years & 13 & 13 & 1 & 27 \\
\hline 10 to 15 years & 5 & 13 & 4 & 22 \\
\hline 15 to 20 years & & 5 & 12 & 17 \\
\hline more than 20 years & 3 & 14 & 31 & 48 \\
\hline Total & $\mathbf{2 8}$ & $\mathbf{4 7}$ & $\mathbf{5 0}$ & $\mathbf{1 2 5}$ \\
\hline
\end{tabular}

Table 3: Breakdown of respondents' teaching experience by rank

\subsection{Responses}

Survey participants were given a formal definition of Peer Instruction and asked about their familiarity with it. The breakdown of answers can be seen in Table 4. That particular survey question was used to divide the 125 respondents into 3 groups. Members of the "Unaware" group are faculty who know nothing about PI; respondents in the "Experience" group either adopted and currently use PI, have used it in the past but abandoned it, or use PI and encourage others to adopt it as well; while the "Rejecters" group consists of faculty who have knowledge of PI but choose not to implement it.

\begin{tabular}{|l|c|c|}
\hline Response & Count & Group \\
\hline $\begin{array}{l}\text { I am unfamiliar with the described } \\
\text { Peer Instruction technique }\end{array}$ & 21 & Unaware \\
\hline $\begin{array}{l}\text { I am familiar with the described Peer } \\
\text { Instruction technique, but do not use it }\end{array}$ & 53 & Rejecter \\
\hline $\begin{array}{l}\text { I use the described Peer Instruction } \\
\text { technique, or something similar to it }\end{array}$ & 17 & $\begin{array}{l}\text { Experience } \\
\text { (Adopter) }\end{array}$ \\
\hline $\begin{array}{l}\text { I use the described Peer Instruction } \\
\text { technique, or something similar to it; } \\
\text { and encourage others to use it }\end{array}$ & 25 & $\begin{array}{l}\text { Experience } \\
\text { (Evangelist) }\end{array}$ \\
\hline $\begin{array}{l}\text { I have used the described Peer } \\
\text { Instruction technique, or something } \\
\text { similar to it; but no longer use it }\end{array}$ & 9 & $\begin{array}{l}\text { Experience } \\
\text { (Abandoner) }\end{array}$ \\
\hline
\end{tabular}

Table 4: Breakdown of answers to the question "How aware are you of the Peer Instruction technique, as roughly described above?" [Q10]

4.3.1 The "Unaware" Group. The majority of respondents stating that they were unaware of PI came from mostly medium size institutions, 20 of which were in North America and 1 in Asia. Of the 21, 10 reported their experience as "more than 20 years" with 7 of them in a senior rank. Faculty in this group predominantly pointed to colleagues and the Internet as their primary source of information about pedagogic innovation. When asked about rewards existing for the adoption of new pedagogies, over half (12) of the faculty members in the group named "satisfaction", 7 stated that there were no rewards, while only 3 respondents pointed to improved student success and retention. One non-tenured early-rank participant with 10-15 years of experience from a North American medium-size institution wrote that not only were there no rewards but there were penalties like loss of tenure and no reappointments for "departing the norms of senior colleagues".
4.3.2 The "Rejecters" Group. The group of respondents that stated they were familiar with Peer Instruction but chose not to use it consisted of faculty from 49 institutions in North America, as well as 3 in Australasia and 1 in Europe. Participants in this group were mostly from very small or very large institutions and from institutions that were almost exclusively awarding baccalaureate degrees and above. Of this "rejecters" group 74\% (39) answered that they had 10 or more years of teaching experience in computing and $85 \%$ (45) had mid- or senior-level rank. 36 of the 53 respondents in this group reported having tenure.

Rejecters were asked to estimate their level of awareness of PI. The question received 49 responses. Over half (26) of faculty said they were "Aware: I know of Peer Instruction from having read about it and/or seen presentations about it", while 15 answered that they were "somewhat aware" from having informal conversations with colleagues. Another 4 responded that they had very minimal undetailed knowledge, while 4 said they were "Very Aware: I have read extensively about Peer Instruction".

When asked to select what they perceived as the most significant benefit of PI, 37\% of respondents in this group pointed to the potential to improve student understanding of the course content. Second place with $16 \%$ each of the vote was shared by increasing engagement or interest in the course content and increasing student participation. 3 tenured senior rank faculty with 15 or more years of teaching experience wrote in that they saw no possible benefits either because they were not convinced the PI approach worked or because there would be no improvements compared to the teaching methods they were currently utilizing.

The most significant reason not to use PI named by the rejecters was "I am satisfied with how I teach now" closely followed by "I have not had enough time to try Peer Instruction" and "Using Peer Instruction might negatively impact my ability to cover material". Additional concerns included a large class size and a course subject that may not be a good fit. Other reasons named were the unfamiliarity with required logistics and resources, time required to integrate PI into their course, the compatibility of other teaching methods or online classes with PI, a fear that class time would become test time and students would not participate equally, discouragement from colleagues, reservations about students liking the approach or coming to class prepared, as well as an outright rejection of the pedagogy.

A myriad of self-composed responses was collected as an answer to the question "What could persuade you to try Peer Instruction?". Participants were free to write anything as an answer. Over a quarter of the respondents said that they might be willing to try PI if there were publicly available resource materials. The lack of time to devote to developing a PI class was mentioned by $20 \%$ while $7 \%$ asked for instructions on how to set up a PI-centered course. 15\% wanted to first see the pedagogy in action in a similar course and be able to discuss with colleagues that already have experience. A little over a tenth of respondents expressed that their courses are not a good fit for the pedagogy in subject or in format, and $10 \%$ feared that PI activities would take up too much class time. 2 instructors thought that PI might improve student engagement if they taught larger courses while another one expressed the opposite view - that a smaller class would be better. 6 of the 41 responses expressed a positive attitude towards PI with half of them saying they have 
concrete plans for implementing it in their courses. 3 faculty needed to see more research to be convinced that the approach works or is not harmful to underrepresented students in beginner courses; 2 survey participants expressed the view that students are negatively biased towards clickers; and one respondent said that they fear it will impact student course evaluations. Another respondent wrote that an argument for PI would be getting encouragement from colleagues, while another said that students coming to class unprepared was an argument against. One faculty was adamant that they will not be implementing PI in their courses as they already use other techniques, and another said there was nothing that could convince them to give the pedagogy a try.

Rejecters named colleagues (77\%), conference presentations (64\%), the Internet (57\%), and professional literature (29\%) as the sources where they learn about new approaches to teaching. The group named satisfaction $(79 \%)$, rank (9\%), money $(8 \%)$, and awards (4\%) as rewards for implementing pedagogic innovations. 7 of the 53 respondents said there were no rewards, while 8 said that the rewards were better student outcomes and improved learning, motivation, and engagement. One non-tenured mid-rank faculty member with 15-20 years of teaching experience employed at a very large institution commented "unclear - we want it for lip service, but what we really want is increased graduation rates", while a senior-rank tenured respondent from a large institution with more than 20 years of teaching experience wrote "applying new teaching techniques is built into both our performance reviews and our tenure process although in practice, it is only a small part of each".

4.3.3 The "Experience" Group - Adopters, Abandoners, and Evangelists. Survey respondents who indicated they knew about PI could be split into three subgroups - the "adopters", who currently use the approach, the "abandoners" that have used it in the past but have since stopped, and the "evangelists" - those who not only use PI but encourage others to adopt it as well.

While the adopters and evangelists are fairly evenly distributed among ranks, $78 \%$ of abandoners reported they had senior-level rank. $60 \%$ of evangelists and $76 \%$ of adopters came from medium to very large institutions.

Survey participants were asked to name the duration of their own use of the PI technique. The response breakdown can be seen in Table 5. Nearly half the abandoners reported stopping the use of PI after their second semester. The majority of adopters and evangelists continue their use beyond their fifth semester.

\begin{tabular}{|l|c|c|c|c|}
\hline $\begin{array}{l}\text { Semesters } \\
\text { Using PI }\end{array}$ & Adopter & Abandoner & Evangelist & Total \\
\hline 1 & & 1 & 3 & 4 \\
\hline $2-5$ & 6 & 7 & & 13 \\
\hline $6-10$ & 5 & 1 & 13 & 19 \\
\hline more than 10 & 3 & & 9 & 12 \\
\hline no response & 3 & & & 3 \\
\hline
\end{tabular}

Table 5: Distribution of responses to the question "How many terms (quarters, semesters) have you used Peer Instruction?” for the Experience group [Q17]
As presented in Table 6, the computing course most used with PI is CS1 Introduction to Programming. Judging by the data, adopters and evangelists spread the use of this pedagogy to other courses including non-computing ones. More than 20 other computing courses using PI were reported by one or more faculty members, including: Software Engineering, Programming Languages, Operating Systems, Computer Networks, Computer Architecture, Computer Organization, Human-Computer Interaction, Artificial Intelligence, Digital Circuits, Software Development, Computer Hardware, Advanced Data Structures, Database Design, Data Mining, Intro to Machine Learning, Web Apps with Databases, Intro to EECS using robots, Intro to Linux, Intro to Robotics, User Interface Software Development, Intro to Functional Programming and CS electives at all levels. Other non-computing courses named were Ethics, Introductory Physics, Discrete Math, Linear Signals and Systems, Intro to Professional Practice, Critical Thinking, and Information Management.

\begin{tabular}{|l|c|c|c|c|}
\hline PI Courses & Adopter & Abandoner & Evangelist & Total \\
\hline CS0 & 2 & & 6 & 8 \\
\hline CS1 & 7 & 3 & 16 & 26 \\
\hline CS1.5 & 3 & 1 & 6 & 10 \\
\hline CS2 & 3 & 3 & 8 & 14 \\
\hline other & 6 & 3 & 18 & 27 \\
\hline
\end{tabular}

Table 6: Courses with PI practice taught by the Experience group [Q18 (multi-select)]

As shown in Table 7, the majority of faculty currently or previously involved with PI wrote their own questions. This may be due to the lack of public sources or to faculty being unaware of available resources. An abandoner who used PI for a single semester mentioned using Eric Mazur's book. Two adopters wrote that they use online sources, while one evangelist named Ranjit Jhala and Nadia Poliparkova as sources of questions and another 2 used peerinstruction4cs.org.

\begin{tabular}{|l|c|c|c|c|}
\hline $\begin{array}{l}\text { Question } \\
\text { Source }\end{array}$ & Adopter & Abandoner & Evangelist & Total \\
\hline private source & 2 & & 6 & 8 \\
\hline public source & 2 & 1 & 3 & 6 \\
\hline self-written & 14 & 9 & 23 & 46 \\
\hline other & 1 & 1 & 3 & 5 \\
\hline no response & 2 & & & 2 \\
\hline
\end{tabular}

Table 7: Source of ConcepTest questions used by the Experience group [Q25 (multi-select)]

Tables 8-11 show the manner in which PI users responding to the survey implement(ed) the pedagogy. Adopters and evangelists appear to exhibit stricter adherence to the PI protocol although variations and adaptations occur. Almost half of the abandoners report not using reading quizzes at all. Only $12 \%$ of evangelists said they didn't use reading quizzes and $20 \%$ of them said they spread such activities throughout the class. The majority of the Experience 
group makes use of electronic response devices with immediate feedback such as dedicated clickers or mobile devices/computers equipped with special apps capable of recording answer choices.

\begin{tabular}{|l|c|c|c|c|}
\hline $\begin{array}{l}\text { Do you assign } \\
\text { specific } \\
\text { readings } \\
\text { for each class }\end{array}$ & Adopter & Abandoner & Evangelist & Tot \\
\hline always & 7 & 3 & 6 & 16 \\
\hline ca. half the time & 2 & 2 & 3 & 7 \\
\hline frequently & 4 & 2 & 8 & 14 \\
\hline infrequently & 1 & 1 & 6 & 8 \\
\hline never & 1 & 1 & 2 & 4 \\
\hline no response & 2 & & & 2 \\
\hline
\end{tabular}

Table 8: Reading assignment for the Experience group [Q19]

\begin{tabular}{|l|c|c|c|c|}
\hline $\begin{array}{l}\text { Do you employ } \\
\text { reading quizzes } \\
\text { or pre-class } \\
\text { activities for } \\
\text { each class }\end{array}$ & Adopter & Abandoner & Evangelist & Tot \\
\hline always & 6 & 2 & 5 & 13 \\
\hline ca. half the time & 1 & 1 & 5 & 7 \\
\hline frequently & 3 & 2 & 6 & 11 \\
\hline infrequently & 4 & & 6 & 10 \\
\hline never & 1 & 4 & 3 & 8 \\
\hline no response & 2 & & & 2 \\
\hline
\end{tabular}

Table 9: Quiz or activity assignment for the Experience group [Q20]

\begin{tabular}{|l|c|c|c|c|}
\hline $\begin{array}{l}\text { When do PI } \\
\text { reading quizzes } \\
\text { or activities } \\
\text { occur }\end{array}$ & Adopter & Abandoner & Evangelist & Tot \\
\hline in class & 5 & 4 & 7 & 16 \\
\hline before class & 7 & 1 & 10 & 17 \\
\hline other & 3 & 4 & 8 & 16 \\
\hline no response & 2 & & & 2 \\
\hline
\end{tabular}

Table 10: Quiz or activity timing for the Experience group [Q21]

$76 \%$ of evangelists structure their class as individual vote, followed by small group discussion, followed by either a group vote or a second individual vote. Adopters and abandoners on the other hand employ one of these two approaches or use individual or small group voting only and no preference for any one of these methodologies emerges from the survey responses. Figure 2 shows the overall class time spent on activities for each of the three subgroups with experience in PI, and how their approaches compare to each other.

\begin{tabular}{|l|c|c|c|c|}
\hline $\begin{array}{l}\text { How do } \\
\text { students } \\
\text { respond to } \\
\text { questions }\end{array}$ & Adopter & Abandoner & Evangelist & Tot \\
\hline dedicated clickers & 7 & 3 & 14 & 24 \\
\hline $\begin{array}{l}\text { phones (or } \\
\text { tablet/computer } \\
\text { app or online) }\end{array}$ & 5 & 3 & 16 & 24 \\
\hline paper & 4 & 1 & 4 & 9 \\
\hline show of hands & 1 & 1 & & 2 \\
\hline no response & 2 & & & 2 \\
\hline
\end{tabular}

Table 11: Methods of response collection for the Experience group [Q22 (multi-select)]

\section{Comparison of Class Structure}

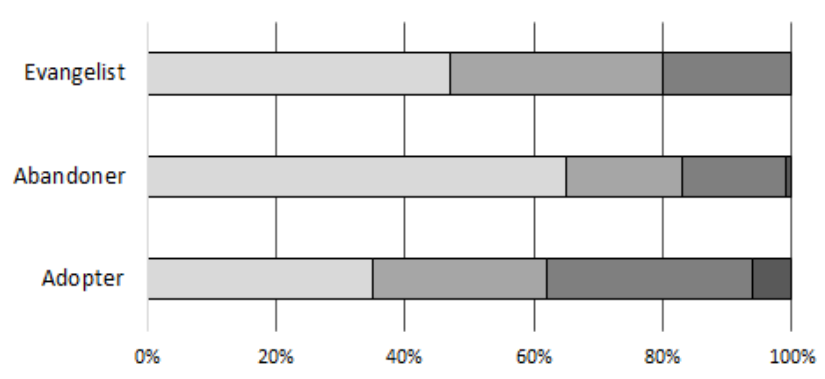

$\square$ presenting new material $\square$ question sessions $\square$ other activities $\square$ other

Figure 2: Comparison of class structures for the Experience group [Q24]

Tables 12 and 13 represent the responses of the Experience group when faculty were asked to name the major benefit of PI and the leading reason not to use PI. Two evangelists added benefits for use as "having to teach something is a great way to learn" and having immediate feedback on students' understanding. One senior-rank abandoner who used PI for 2 semesters wrote the following "I felt that most of the small groups did not have anyone in the group who understood sufficiently well to come to an adequate conclusion. I did not have enough 'smart' kids in the classroom." Other notable comments made by abandoners regarding reasons not to use PI were difficulty coming up with good questions, different learning styles of students, and the possibility of negative impact on tenure.

Everyone in the Experience group was asked an open ended question about their impression of students' view of PI. Over half of the abandoners wrote that students responded positively. Some added that PI improved student engagement and retention of material, kept class interesting, and students had fun and enjoyed the immediate feedback and the ability to practice. One abandoner wrote that PI only serves a subset of students and annoys the students that are well prepared, and another wrote that PI makes students feel like the faculty member is not really teaching. All adopters responding to the question wrote that students like the pedagogy. Some added that students generally like discussing with peers and 


\begin{tabular}{|l|c|c|c|c|}
\hline Benefit & Adopter & Abandoner & Evangelist & Tot \\
\hline $\begin{array}{l}\text { better “fit" with } \\
\text { learning } \\
\text { style }\end{array}$ & 1 & 2 & 2 \\
\hline $\begin{array}{l}\text { better prepare } \\
\text { students' careers }\end{array}$ & 1 & 3 & 13 & 19 \\
\hline $\begin{array}{l}\text { improve students' } \\
\text { class performance }\end{array}$ & 3 & 3 & 7 & 19 \\
\hline $\begin{array}{l}\text { improve students' } \\
\text { understanding of } \\
\text { course content }\end{array}$ & 9 & 2 & 1 & 4 \\
\hline $\begin{array}{l}\text { increase students' } \\
\text { engagement or } \\
\text { interest }\end{array}$ & 2 & 1 & 1 & 4 \\
\hline $\begin{array}{l}\text { increase students' } \\
\text { participation }\end{array}$ & 1 & 13 & 2 \\
\hline $\begin{array}{l}\text { no response } \\
\text { or other }\end{array}$ & 2 & & 13 & 19 \\
\hline
\end{tabular}

Table 12: Leading benefit of PI as voted by the Experience group [Q27]

\begin{tabular}{|c|c|c|c|c|}
\hline Reason against & Adopter & Abandoner & Evangelist & Tot \\
\hline $\begin{array}{l}\text { not familiar } \\
\text { with logistics }\end{array}$ & & & 1 & 1 \\
\hline no resources & 1 & & & 1 \\
\hline no time & 1 & 2 & 2 & 5 \\
\hline $\begin{array}{l}\text { department sets } \\
\text { curriculum }\end{array}$ & 1 & & 2 & 3 \\
\hline $\begin{array}{l}\text { enrollment } \\
\text { too large }\end{array}$ & 2 & & 1 & 3 \\
\hline $\begin{array}{l}\text { enrollment } \\
\text { too small }\end{array}$ & & & 1 & 1 \\
\hline $\begin{array}{l}\text { physical setup } \\
\text { of classroom }\end{array}$ & 2 & & 1 & 3 \\
\hline $\begin{array}{l}\text { students might } \\
\text { dislike PI }\end{array}$ & & & 1 & 1 \\
\hline $\begin{array}{l}\text { doesn't fit } \\
\text { course }\end{array}$ & 3 & & 2 & 5 \\
\hline $\begin{array}{l}\text { doesn't fit } \\
\text { student type }\end{array}$ & 1 & 1 & & 2 \\
\hline $\begin{array}{l}\text { no evidence } \\
\text { PI works }\end{array}$ & & 1 & & 1 \\
\hline $\begin{array}{l}\text { negative impact } \\
\text { on ability to } \\
\text { cover material }\end{array}$ & 1 & 2 & 6 & 9 \\
\hline $\begin{array}{l}\text { satisfied with } \\
\text { how i teach now }\end{array}$ & 1 & 2 & 1 & 4 \\
\hline $\begin{array}{l}\text { no response or } \\
\text { other }\end{array}$ & 4 & 1 & 2 & 7 \\
\hline none & & & 5 & 5 \\
\hline
\end{tabular}

Table 13: Leading reason not to use PI as voted by the Experience group [Q29] application of concepts but those who do not like to work before class may struggle. 22 of the 25 evangelists answered the same question. All said that students liked PI and 4 of them supported that statement with evidence from student evaluations. Evangelists' answers also indicate that some of these faculty members have introduced variations of the method and explain the educational benefits to their students. 3 evangelists mentioned that students who were not prepared had trouble.

When abandoners were asked why they stopped using PI, the answer selected most often by the majority of respondent was "Using Peer Instruction negatively impacted my ability to cover material" followed by "My students do not like it" and "My students did not learn". 2 of the 9 abandoners said that developing enough good questions was a major hurdle. 1 said that they only abandoned PI because they retired and another said that the reason was "personal laziness".

Evangelists were asked why they encourage others to use PI. 90\% said that it's because it is effective. They said the method enhances learning, and improves outcomes, engagement, and performance. Some also said that PI improves attendance and participation, especially for students that are otherwise too shy to speak in class. Opinions included favor for PI because conversation results in better understanding of material, and both students and teacher receive immediate feedback. One evangelist said it makes teaching more enjoyable, another wrote that interactivity replaces boring lectures, and another posited that PI "takes burden of instruction off teacher and distributes [it] to student-teachers".

All responding evangelists wrote that they encourage others to use PI by informally discussing the method with them, sharing their own experience, or discussing the methodology's strengths. Some proactively offer help in the form of answering questions, holding workshops, inviting faculty to view PI in action, assisting instructors interested in trying it out, and co-teaching classes with colleagues. Half of evangelists recognize the hurdle of authoring and finding materials so they share theirs with others. Table 14 shows how Experience group members answered the question about where they learn about innovations in teaching.

\begin{tabular}{|l|c|c|c|}
\hline $\begin{array}{l}\text { Sources of } \\
\text { pedagogic } \\
\text { innovation }\end{array}$ & Adopter & Abandoner & Evangelist \\
\hline colleagues & $65 \%$ & $78 \%$ & $80 \%$ \\
\hline conferences & $47 \%$ & $67 \%$ & $76 \%$ \\
\hline professional literature & $65 \%$ & $44 \%$ & $72 \%$ \\
\hline internet & $71 \%$ & $56 \%$ & $64 \%$ \\
\hline E. Mazur book & & $11 \%$ & \\
\hline institution & $6 \%$ & $11 \%$ & $16 \%$ \\
\hline
\end{tabular}

Table 14: Sources of information on pedagogic innovation for the Experience group [Q34 (multi-select)]

All three subgroups in the Experience group pointed to satisfaction as a reward for adopting pedagogic innovation. The breakdown of answers is presented in Table 15. As other reasons not captured by the possible answers in the survey, one abandoner wrote "a dean may give public kudos to colleagues trying to innovate (no matter 
if it's actually better instruction or not!)" and one evangelist added the possibility of improved student reviews. A large portion of the survey respondents in the Experience group and across the board felt that trying out new teaching methods was not rewarded at all.

\section{ANALYSIS OF SURVEY RESPONSE}

Some conclusions can be cautiously drawn from the survey responses.

Computing instructors unaware of PI may not have come across it because they do not actively seek out information about new pedagogies or consult sources like conference proceedings and professional literature but rely on the Internet and colleagues instead. As already noted earlier however, there is very scarce literature on the topic of PI in computing. It is also possible, as the responses indicated, that institutions may not reward innovation in teaching or may even actively discourage it.

Rejecters seem predominantly to be instructors with over a decade of experience, have mid-level or senior ranks, and often have tenure. Judging by respondent's answers about why they choose not to utilize PI, these instructors are satisfied and comfortable with the way they teach classes. They do not wish to try out anything new that may not work as well as what they are presently doing. This may be because they don't believe the course fits PI or students will not prepare or participate to make the approach successful. Some mentioned discouragement from colleagues as a reason not to try PI, and that would be a very strong demotivator since rejecters pointed to colleagues as their primary source of pedagogy innovation. The shortage of research literature may also play a role, since some in this group cited lack of evidence that PI works and were unsure of the proper class size.

A portion of the rejecters indicated that they were open to giving PI a try but had no time to develop materials and had no information on how to properly set a PI-centered course. Considering that the majority of these instructors are in mid- and senior level ranks, it is very plausible that they simply do not have the extra time to re-develop courses they already have a comfortable way of teaching. Publicly available resources for a variety of course topics and logistical information, as well as encouragement from colleagues may possibly turn these rejecters into adopters. Of course there were those that were adamant that PI will never become part of their curriculum.

Abandoners appear to be mostly senior rank faculty. They give up PI after the second semester of using it. Abandoners indicate that they dedicate the majority of class time to presenting new material, and some point to PI negatively impacting their ability to cover material. Thus abandoners may not be making proper use of PI, which means to dedicate time to test and strengthen students' understanding of concepts they should have already been presented with in pre-class readings. In contrast, adopters and evangelist dedicate far less time on lecturing and instead spend about double the time that abandoners do on question sessions. Many abandoners also do not assign reading quizzes, implying that students may be encouraged to underprepare. All three subroups in the "Experience" group noted that students who were unprepared struggled. The attitudes of struggling students may sharply veer into the negative. That can sour the whole PI experience if enough of the class is unprepared or not incentivized to do the work before class. Hence the abandoners' comments that they abandoned PI because their students didn't like it and didn't learn.

Most abandoners also write their own questions, which is a very time-consuming task, especially in the first few semesters developing and refining a PI course. Poorly written questions may push instructors towards abandonment, so it would be vital to present new adopters with a bank of tested ConcepTests to help them develop the course and improve their and their students' experiences. Another issue that may turn adopters into abandoners as indicated by the survey responses and the working group members' own experiences is the availability or lack thereof of response devices and/or software to collect and present student answers.

Just like abandoners, the majority of adopters and evangelists also indicate that they write their own questions. It is possible that the computing education community is unaware of publicly available resources. These available resources however are far from comprehensive and up-to-date so there is a need to develop more materials and make them available to the community in support of those willing to try PI or improve their PI courses.

Institutions of evangelists support and advance PI, and in turn evangelists encourage and support peers willing to try the approach in their classrooms. Evangelists also propagate PI beyond introductory computing. There are PI resources created for a myriad of courses, but they are not being widely shared.

\subsection{Barriers}

Two of the most cited arguments against adopting PI are the lack of time and guidance to develop course materials and the lack of available resources. It is vital to expand the bank of available materials already developed by the PI community and share them with instructors who may be interested in trying out Peer Instruction. It is also important to make logistics materials and support available to those new to PI. Encouragement by colleagues and having the ability to see PI in action could create more adopters.

No availability of polling devices and/or software may also have a negative impact, so institutions making a small investment in clickers and/or software for computers or mobile devices would be a positive step toward supporting instructors who want to improve student engagement in their classroom. Currently it is often the case that an instructor who wants to integrate PI must not only devote time to figure out the best way to redesign a course and develop their own materials, but must also seek out the best (free) technology solution that could be used in their classroom.

The lack of institutional support for teaching is also a big obstacle for the adoption of PI. So is the uncertainty of faculty of how PI will influence student attitudes (and with this, student evaluations). Another issue is instructors being unsure of how the implementation of Peer Instruction will impact their ability to cover material, how well the methodology will fit in with the course subject, class size, and student learning styles and demographic makeup. More research showing the successful use of PI could assuage these doubts, as could workshops, hands-on demonstrations, and help from peers. 


\subsection{Motivation}

Table 15 lists the answers of all survey respondents when asked about existing rewards for adopting pedagogic innovations. Personal satisfaction is the leading response across the board and the responses indicate that most institutions are not supportive and do not offer recognition of new teaching approaches. Some institutions and faculty groups even actively discourage departing from the established teaching methods. It is clear that personal satisfaction and better classroom experiences and outcomes are already big motivators, but institutions could encourage faculty interested in trying out PI (and other innovative teaching methods) to adopt it by assigning a higher value to teaching.

\begin{tabular}{|c|c|c|c|c|c|}
\hline \multirow[b]{2}{*}{$\begin{array}{l}\text { Rewards for } \\
\text { adopting } \\
\text { pedagogic } \\
\text { innovations }\end{array}$} & \multicolumn{3}{|c|}{ Experience group } & \multirow{2}{*}{$\begin{array}{l}\text { Unaware } \\
\text { group }\end{array}$} & \multirow{2}{*}{$\begin{array}{l}\text { Rejecters } \\
\text { group }\end{array}$} \\
\hline & $\frac{\sqrt{5}}{\frac{\pi}{2}}$ & 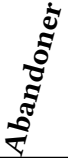 & 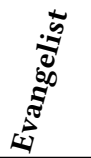 & & \\
\hline satisfaction & $47 \%$ & $78 \%$ & $88 \%$ & $57 \%$ & $79 \%$ \\
\hline money, awards & $6 \%$ & & $8 \%$ & & $12 \%$ \\
\hline rank & $24 \%$ & $11 \%$ & & $5 \%$ & $9 \%$ \\
\hline none & $35 \%$ & $11 \%$ & $16 \%$ & $33 \%$ & $13 \%$ \\
\hline $\begin{array}{l}\text { student } \\
\text { learning/ } \\
\text { outcomes/ } \\
\text { motivation/ } \\
\text { engagement }\end{array}$ & $18 \%$ & $33 \%$ & $8 \%$ & $14 \%$ & $15 \%$ \\
\hline other & & $22 \%$ & $8 \%$ & $10 \%$ & $4 \%$ \\
\hline no response & $12 \%$ & & & & \\
\hline
\end{tabular}

Table 15: Rewards for adopting pedagogic innovation as answered by all survey respondents [Q35 (multi-select)]

\subsection{Evangelization}

Evangelists see the leading benefits of PI as improving students' understanding of course content and their engagement. Even though the majority of them consider the main reward for adopting teaching innovation to be personal satisfaction and see that these activities do not translate into higher rank, more money, or awards, they keep using and propagating PI. This could only mean that evangelists find a great deal of value in Peer Instruction for both themselves and their students and want to share this with colleagues.

\subsection{Threats to Survey Validity}

The survey mailing lists were skewed towards institutions on one continent - 119 of the 125 were from North America, 3 from Australasia, 2 from Asia, 1 from Europe. The survey was also only offered in English, so a possible language barrier may have discouraged instructors from locations where English is not the main language from participating.

\section{DISCUSSION}

\subsection{Results from Literature Review}

According to the available research, adoption of Peer Instruction in computing classrooms is low. The literature needed to propagate the knowledge of the technique in the field of CS education is sparse, not easy to find unless one is specifically looking for it, and the majority of related work stems from the same authors. All of these factors may discourage potential adopters or make them question the validity of the body of research concerning the effectiveness of PI.

Studies about PI in both CS and STEM disciplines repeatedly point to measurable learning gains for students, a reduction in attrition rates, and positive student attitudes. All of these findings should encourage instructors to try out PI, but it's not clear whether this research even reaches most CS faculty.

Outside of knowledge of a pedagogy, other factors can strongly influence its adoption. The lack of time is the reason most named by faculty not implementing new approaches in the classroom. Institutions not supporting or actively discouraging teaching innovation or simply not valuing teaching can also become an insurmountable barrier when faculty feel they have no incentive to innovate or doing so may negatively affect their status. Personal factors like instructors doubting their knowledge and abilities to implement instructional strategies can also become a hurdle.

Getting instructors to try PI is difficult but so is preventing them from abandoning it. The literature emphasizes the importance of the correct implementation of pedagogy with mindful minor modifications if necessary.

More research needs to be done to develop strategies to propagate knowledge, encourage and support faculty in trying out PI specifically in computing, and make sure they use the technique correctly so students can benefit from better learning outcomes and experiences.

\subsection{Results from PI Stories}

Members of this working group come from a variety of institutions, large and small, public and private, ranging from 2-year to doctoral level. All of us, unsurprisingly, were interested in using PI as an instrument to increase student engagement with the coursework, while some also had a particular interest in targeting underrepresented groups and students in need of additional academic support. Many of us were successful in implementing PI practices in introductory programming courses, but some also applied it in more advanced courses, such as algorithms and software engineering.

As a result of PI we experienced a noticeable improvement in student engagement and motivation leading to better retention rates. In many cases, students in our courses reported gaining an increased sense of community, which further helped them improve their chances of academic success.

Reflecting on our collective experience, the members of this working group identified a number of common concerns related to the successful implementation of PI practices. Although the methodology is straightforward and easy to understand, it is always difficult and time-consuming to develop a set of good ConcepTest questions for anyone who is new to PI and especially when there is no existing work or reports on implementing the methodology in the same 
or similar course. Good ConcepTests typically require one or more rounds of refinement after deployment to improve their quality. They also need continued maintenance to adapt to evolving course material, new or updated readings, as well as possible changes in technology supporting student interaction. It is very important to find the right balance between PI-centric student discussions and introducing core course material. This is especially relevant in fastpaced courses packed with hands-on practice, such as introductory programming. At the same time, courses like CS1 and CS2 may be a better fit for implementing PI because this type of course material more naturally leads to developing questions with a set of clearly defined short answers.

\subsection{Results from Survey}

The "Unaware" group of survey respondents could have been expected to consist of mostly young faculty with limited teaching experience but it was not the case. Due to the sparse research on Peer Instruction in the field of computing, it appears that information about PI and its benefits does not reach a lot of faculty. These instructors' responses however indicate that they don't necessarily turn to professional literature looking for new approaches to teaching, so it's important for the PI community to reach these members in other ways.

The "Rejecters" group had a high level of awareness of PI and it can be concluded that the choice against the pedagogy was conscious and deliberate. The lack of time was indicated to be a major factor. The resistance, some pointed out, was that they were not convinced that PI actually worked, so once again, it appears that more research is necessary to potentially change their opinions. Since under a third of this group mentioned professional literature as a source of information on innovation in teaching, a bigger body of research may not be sufficient to inform them. A portion of this group does seem to recognize that PI has the potential to improve both student outcomes and engagement. Some rejecters' responses suggested that these instructors can be turned into adopters if they were provided with the appropriate support - both logistically and materially. Encouragement from colleagues and the opportunity to see the methodology in action could also create adopters. However, it is quite clear that some rejecters will remain dismissive of the pedagogy because they simply do not want to change the way they teach at present. It is unclear if there is any amount of evidence or incentives that would persuade these instructors to give PI a try.

The "Experience" group deploys PI in a myriad of computing courses with CS1 being the most popular. These instructors have dedicated a lot of time to PI, since the majority of all three subgroups - adopters, abandoners, and evangelists - write their own ConcepTest questions. The survey respondents who abandoned Peer Instruction mostly did so after 2 semesters. Judging by the organization of class activities however, it is plausible to assume that abandoners fail because they do not conduct the PI cycle properly. They indicate that two thirds of their class time is still spent presenting new material to students - something that should have been accomplished with pre-class activities. It's possible that guidance from experienced PI users during the initial semesters of deployment could have prevented these faculty from abandoning the technique.

\subsection{PI Implementation Recommendations}

This section offers advice for adopters of PI based on the literature, our experiences, and the results of the survey.

Vickrey et al. [46] outline a clear model for evidence-based PI implementation. The model is designed such that each step leads to the most positive student outcome. It is therefore recommended that the structure given in that model be followed by instructors willing to deploy PI in their courses, especially if they are new to the technique. Steps in this revised PI implementation include posing high-level conceptually challenging questions, having students respond with clickers, analyzing the responses, and having the teacher respond with discussion, re-voting, and explanations, or further questions or moving to another topic as necessary. The potential repercussions from deviating too far from the model by e.g. eliminating steps or revealing answers from the initial vote are presented in [46] as well.

We make some additional recommendations to improve instructors' and students' experiences with PI:

- The "pre-class activity" is an important facet of PI and it encourages students to prepare for class. Find a way to automate the grading of this activity.

- "Participation points" are an essential component of PI. Find a way to automatically award participation points, and make students aware of their participation points. Be aware that awarding points for correctness instead of participation may introduce bias and diminish learning gains.

- Possible tools: given that part of the instructor's classroom performance depends on collecting student responses in real-time, there are choices: electronic, paper, raised hands. The choice depends on what is available to the instructor/institution. However, if possible, opt for electronic means of response collection - with dedicated clickers or software that can be installed on computers or mobile devices provided by the school or the students themselves. Of course, not all tools are created equal or are equally affordable. Having electronic response collection enables a) statistic presentation in class, b) awarding of 'participation points' for students, c) recording the class success rate for the question posed, d) provides real-time feedback to both students and teacher.

\subsection{PI Computing Content Recommendations}

Below are lists of resources for those interested in adopting the practice of Peer Instruction, including tutorials for teaching with PI, PI questions for computing courses, and PI research.

- Tutorials for teaching with PI:

- The Peer Instruction for Computer Science website provides advice on how to get started, best practices, and things not to do.

https://www.peerinstruction4cs.org/

peer-instruction-advice/

- Beth Simon's website offers advice on how to prepare and implement a PI course.

https://cseweb.ucsd.edu/ bsimon/PI/

- Computing Education Research Blog. 
https://computinged.wordpress.com/tag/ peer-instruction/

- Peer Instruction blog. https://peerinstruction.wordpress.com/

- Carl Wieman Science Education Initiative has insight into using clicker resources in science classes. http://www.cwsei.ubc.ca/resources/clickers.htm

- YouTube https://www.youtube.com/results?search_query=peer+ instruction+computer+science and https://www.youtube. com/results?search_query=peer+instruction

- Stephanie Chasteen workshop video on writing clicker questions. https://www.youtube.com/watch?v=2PpKi0nBrVM

- The Chronicle of Higher Education offers articles and experience reports on Peer Instruction in a broader context. https://www.chronicle.com/blognetwork/ castingoutnines/category/teaching/peer-instruction/

- PI questions:

- A question bank can be found at http://www.peerinstruction4cs.org. Courses with available content include Cyber-Security, Discrete Mathematics, CS1 in Python, MatLab and Java, CS2 in C++ and Java, Operating Systems, Programming Languages, CS principles, Computer Architecture, Theory of Computation.

- The Canterbury QuestionBank [37] contains hundreds of multiple-choice computer science questions that could be adapted to ConcepTests.

http://web-cat.org/questionbank/

- PI research:

- Peer Instruction for Computer Science website https://www.peerinstruction4cs.org/latest-research/

- Daniel Zingaro's website http://www.danielzingaro.com/pics.php

- The ACM digital library https://dl.acm.org/

\subsection{Future Work}

More work needs to be done to put PI in front of a larger portion of the CS community and increase adoption. The future work includes research and non-research items:

- Research The survey can be redone and redistributed, this time to a wider multi-national audience of CS instructors. This will require the creation of an extensive mailing list. While the respondents remain anonymous, it may be interesting to include additional data points like gender. Some research indicates that women are more likely to try and stick with new teaching methods, so it would be interesting to see what proportion of experienced users and rejecters are female. The survey should also be translated in multiple languages and distributed to instructors in the language appropriate for their location in order to encourage participation and diminish language bias.
- Non-Research It is vital to create and promote a publicly available repository for PI materials for different computing courses and curricula. The materials can be tested by instructors and continually improved and refined. Thus the major barrier - the lack of time to devote to transforming a course - can be overcome. The PI community can work to either consolidate sources or replicate and propagate available materials to multiple already know sites in order to reach a wider audience.

- Non-Research It is important to create a support network especially for faculty new to PI, be it by educating unaware instructors or guiding new adopters. This can be done by providing training, organizing workshops, co-teaching, or being available to answer questions.

\section{CONCLUSION}

The literature, the authors' experiences, and the survey results converge on the same barriers to adoption of Peer Instruction in computing courses. Faculty have no time to implement PI or don't know how. Their institutions do not support or value teaching innovation. They are not sure how PI will fit their students/classroom/course. The availability of technology is uncertain. There are no publicly available resources, there is not enough research.

It is clear that the time issue is not simple to resolve. Institutions, especially those with emphasis on research, often do not assign much significance to teaching. Not giving an equal or higher than current value to student instruction as part of faculty's advancement deters instructors from dedicating time and effort to implementing innovative approaches to teaching even if their effectiveness is backed up by a body of research. Institutional support for productive and engaging teaching is crucial. Incentives could help. It is also very important for institutions and colleagues to not actively discourage faculty from innovating in the classroom. Punishing faculty for receiving mixed or bad evaluations in the first semesters of trying out a new teaching approach can be a major deterrent.

Changing institutional culture may not be enough if faculty's perception of their own academic identity is as a research scientist first and a teacher second. In order to innovate effectively, instructors need to be at least equally devoted to achieving excellence in teaching. Entering a classroom and giving a lecture is easier than continually trying to deliver an engaging, interactive, and challenging learning session. Faculty dedication to becoming better teachers is paramount.

In order to cut down on preparation time however, the PI community can provide assistance to instructors new to PI. Organizing workshops, providing opportunities to see PI in action in different classrooms/institutions/subjects, closely supporting new adopters in the first semesters with advice, encouragement, logistics and materials are all ways to motivate instructors that are willing to try Peer Instruction. It is also crucial to ensure that faculty properly implement the PI cycle so they are not moved to become abandoners. Most importantly, we need banks of tested ConcepTest questions, as much to assist new adopters as to extend the repertoire of everyone using PI. Publicly available materials for a variety of subjects can potentially dissolve the doubt that some instructors have that PI 
may not be a god fit for their course and can show them how much material can be covered with properly structured assigned readings and suitable ConcepTest questions.

A larger body of research on learning gains due to PI, student and faculty perceptions, student engagement and retention, on application in different subjects and with various class sizes could propagate the methodology through the computing faculty community. This evidence coupled with support and publicly available materials could inform the unaware, motivate the rejecters to become adopters, and keep abandoners in the adoption phase.

\section{ACKNOWLEDGMENTS}

"Team Panda" would like to thank the CompEd conference organizers for hosting Working Groups; and to the on-site conference staff who facilitated our work. We also acknowledge the USA National Science Foundation for providing travel support to some attendees. Thanks are also due to the reviewers of the draft report, who served to improve this paper.

\section{A APPENDIX: SURVEY}

Q1. Eric Mazur popularized the Peer Instruction teaching approach in collegiate Physics courses in the 1990s. Since that time, instructors have used Peer Instruction in philosophy, psychology, math, engineering, and computer science.

This study aims to assess computing instructors' attitudes regarding Peer Instruction. In more detail, we are studying the reasons why CS instructors choose a) to use Peer Instruction, b) choose not to use Peer Instruction, or c) choose to use Peer Instruction, but later, stop using it.

Your can help in this study by answering this survey. If you choose to respond to the survey, depending on which of the three (above) categories you belong, you may expect to spend between 10 and 30 minutes to complete the survey. The survey begins by collecting general demographic information (such as continent, and years of teaching experience) but no personally identifiable information is requested. Data that describes institutional characterization and instructor position are for the purposes of assessing representation of the responses, and identifying possible trends. The responses will only be reported in aggregate.

While it is possible to self-identify yourself in the free response questions, such a response is discouraged.

Q2. Research Participant Notification

Dennis Bouvier is inviting you to participate in this research study. The title of this study is "Peer Instruction in Computing Courses". The purpose of this study is to study computing instructors' attitudes regarding Peer Instruction. In more detail, we are studying the reasons why CS instructor choose to use Peer Instruction, choose not to use Peer Instruction, or choose to use Peer Instruction, but later, stop using it.

Your participation in this study will involve responding to a survey.

The risks to you as a participant are minimal. These include possible anxiety in responding to the survey.

The results of this study may be published in scientific research journals or presented at professional conferences. However, your name and identity will not be recorded with your response and your record will remain anonymous.

Participation in this study may benefit you by learning about Peer Instruction. Your participation may benefit others by adding to the body of knowledge regarding computing instruction.

You can choose not to participate. If you decide not to participate, there will not be a penalty to you or loss of any benefits to which you are otherwise entitled. You may withdraw from this study at any time.

If you have questions about this research study, you can call Dennis Bouvier at 618-650-2369 or email djb@acm.org. If you have questions about your rights as a research participant, you can call the Southern Illinois University Edwardsville Institutional Review Board at 618-650-3010 or email at irbtraining@siue.edu.

Q3. Where is your institution at which you teach?
$\circ$ Africa
○ Asia
- Australasia
$\circ$ Europe
○ North America
o South America

Q4. In terms of student headcount, what is the approximate size of the institution at which you teach?

- Very Small (less than 3000 students)

- Small (3000 to 6000 students)

○ Medium (6001 to 12000 students)

- Large (12001 to 20000 students)

○ Very Large (more than 20000 students)

Q5. What is the educational focus of the institution?

○ 2-year undergraduate

o 4-year undergraduate

○ Undergraduate and Master-level

- Undergraduate and post-graduate

o other (enter)

Q6. Approximately how many years of computing teaching experience do you have?

○ 0 to 5 years

○ 5 to 10 years

○ 10 to 15 years

○ 15 to 20 years

o more than 20 years

Q7. What is your current rank (pick the one most representative)? o early-rank (Assistant Professor, Lecturer, Level B, Profesor Asociado B, ...)

o mid-rank (Associate Professor, Senior Lecturer, Level C, Profesor Titular A, ...)

o senior-rank (Professor, Reader, Level D/E, Profesor Titular $\mathrm{B}, \ldots)$

Q8. What is your tenure (security of employment) status?

$\circ$ untenured on a tenure-track (potential for security of employment)

$\circ$ tenured (security of employment) on a tenure-track

o non tenure-track position (no potential for security of employment) 
Q9. As mentioned before, Peer Instruction is an instructional approach popularized by Eric Mazur at Harvard University. Instructors use Peer Instruction in various ways; however, these elements are typically present:

1. students are given a reading assignment before the class meeting,

2. a reading quiz, or other pre-class activity, is used to motivate students to complete the reading assignment,

3. in-class question sessions occur in these phases:

1. students answer a question

2. students discuss their answers with other students, attempting to convince their peers of the right answer

3. a second vote, and

4. a discussion of the correct and incorrect answers, led by the instructor.

Q10. How aware are you of the Peer Instruction technique, as roughly described above?

o I am unfamiliar with the described Peer Instruction technique

- I am familiar with the described Peer Instruction technique, but do not use it

○ I use the described Peer Instruction technique, or something similar to it

- I use the described Peer Instruction technique, or something similar to it; and encourage others to use it

o I have used the described Peer Instruction technique, or something similar to it; but no longer use it

Q11. How aware of/familiar with Peer Instruction are you?

- Very Aware: I have read extensively about Peer Instruction

- Aware: I know of Peer Instruction from having read about it and/or seen presentations about it

o Somewhat Aware: I know of Peer Instruction from informal conversations

- Barely Aware: I have only heard of Peer Instruction, but don't know details

o Unaware: I know nothing of Peer Instruction

Q12. Which one, or more, of these items do you see as a benefit(s) of using Peer Instruction?

\ Peer Instruction would increase my students' engagement or interest in course content

口 Peer Instruction would be a better "fit" with how my students learn

口 Peer Instruction would allow me to cover more course content

口 Peer Instruction would improve students' understanding of course content

口 Peer Instruction would improve students' performance in the class

口 Peer Instruction would increase my students' participation in class

$\checkmark$ Peer Instruction would better prepare students for their careers

$\square$ Peer Instruction would be more inclusive of underrepresented students*

口 Peer Instruction would help students improve their social skills

$\square$ other (enter)
Q13. Which one of these items do you see as the most significant benefit of using Peer Instruction?

○ Peer Instruction would increase my students' engagement or interest in course content

○ Peer Instruction would be a better "fit" with how my students learn

- Peer Instruction would allow me to cover more course content

○ Peer Instruction would improve students' understanding of course content

○ Peer Instruction would improve students' performance in the class

○ Peer Instruction would increase my students' participation in class

- Peer Instruction would better prepare students for their careers

○ Peer Instruction would be more inclusive of underrepresented students*

○ Peer Instruction would help students improve their social skills

$\circ$ other (enter)

Q14. Which one, or more, of these items do you consider as reason(s) not to use Peer Instruction?

口 I am satisfied with how I teach now

$\square$ I am not familiar with the logistics/resources needed

$\square$ There is not enough evidence that Peer Instruction works

$\checkmark$ Using Peer Instruction might negatively impact my ability to cover material

- My class enrollment is too large to use Peer Instruction in my course(s)

- My class enrollment is too small to use Peer Instruction in my course(s)

$\square$ Using Peer Instruction might interfere with getting tenure or promotion

I have not had enough time to try Peer Instruction

$\square$ I have not had access to the resources needed to try Peer Instruction

口 Peer Instruction might not work for the type of students I teach

$\square$ My students might not like it

$\square$ My classroom's physical setup prevents me from trying it

$\square$ A colleague or peer has discouraged me from trying it

$\square$ It would not be possible to try it because of how my department sets curriculum

$\square$ Peer Instruction is not a good fit for the course(s) I teach

$\square$ other (enter)

Q15. Which one of these items do you consider as the most significant reason not to use Peer Instruction?

○ I am satisfied with how I teach now

○ I am not familiar with the logistics/resources needed

- There is not enough evidence that Peer Instruction works

○ Using Peer Instruction might negatively impact my ability to cover material

- My class enrollment is too large to use Peer Instruction in my course(s)

- My class enrollment is too small to use Peer Instruction in my course(s) 
- Using Peer Instruction might interfere with getting tenure or promotion

- I have not had enough time to try Peer Instruction

o I have not had access to the resources needed to try Peer Instruction

○ Peer Instruction might not work for the type of students I teach

- My students might not like it

○ My classroom's physical setup prevents me from trying it

- A colleague or peer has discouraged me from trying it

o It would not be possible to try it because of how my department sets curriculum

- Peer Instruction is not a good fit for the course(s) I teach

o other (enter)

Q16. (enter) What could persuade you to try Peer Instruction? (enter something ... even if "I don't know")

Q17. (enter as an integer) How many terms (quarters, semesters) have you used Peer Instruction?

Q18. In which computing course(s) do you use, or have you used, Peer Instruction?

$\square$ CS0 - introduction to computing, with or without some programming

口 CS1 - course focused on introduction to programming

口 CS1.5 - second programming course, with or without some data structures

$\square$ CS2 - course focused on data structures (stacks, queues, ...) and algorithms

$\square$ other (enter)

Q19. When you use Peer Instruction, do you assign specific readings for each class session?

- Always

- Frequently

$\circ$ About $1 / 2$ of the time

$\circ$ Infrequently

o Never

Q20. When you use Peer Instruction, do you employ reading quizzes or pre-class activities for each class session?

- Always

- Frequently

- About $1 / 2$ of the time

○ Infrequently

○ Never

Q21. When do Peer Instruction reading quizzes or pre-class activity occur?

○ Reading quizzes / activity are done on-line before class meeting

- Reading quizzes / activity are done at the start of class meeting (in class)

$\circ$ other (enter)

Q22. When you use Peer Instruction, how do students respond to questions?

$\square$ Mobile phones used as response devices (e.g., poll everywhere, ...)

口 Dedicated electronic response devices (not a mobile phone)

口 Paper response (e.g., "plickers")

$\checkmark$ other (enter)
Q23. When you use Peer Instruction, how is the class session structured?

o Individual voting, followed by small group discussion, followed by a second individual vote

○ Individual voting only

- Small group voting only

- Individual vote, followed by small group discussion, followed by group vote

o other (enter)

Q24. When you use Peer Instruction, how is the class session structured? (total must equal $100 \%$ - you may estimate)

time used for question sessions (enter percent)

time used to present new material (enter percent)

time used on other activities (enter percent)

time for other (enter) (enter percent)

Q25. Who is the author of the Peer Instruction questions you use?

口 I wrote them

$\square$ From a private source

$\square$ From a public source (enter)

$\square$ other (enter)

Q26. Which one, or more, of these items do you see as a benefit(s) of using Peer Instruction?

Peer Instruction would increase my students' engagement or interest in course content

口 Peer Instruction would be a better "fit" with how my students learn

$\square$ Peer Instruction would allow me to cover more course content

口 Peer Instruction would improve students' understanding of course content

口 Peer Instruction would improve students' performance in the class

$\square$ Peer Instruction would increase my students' participation in class

口 Peer Instruction would better prepare students for their careers

$\square$ Peer Instruction would be more inclusive of underrepresented students*

๑ Peer Instruction would help students improve their social skills

$\square$ other (enter)

Q27. Which one of these items do you see as the most significant benefit of using Peer Instruction?

○ Peer Instruction would increase my students' engagement or interest in course content

○ Peer Instruction would be a better "fit" with how my students learn

- Peer Instruction would allow me to cover more course content

○ Peer Instruction would improve students' understanding of course content

o Peer Instruction would improve students' performance in the class

○ Peer Instruction would increase my students' participation in class

○ Peer Instruction would better prepare students for their careers 
- Peer Instruction would be more inclusive of underrepresented students*

○ Peer Instruction would help students improve their social skills

o other (enter)

Q28. Which one, or more, of these items do you consider as reason(s) not to use Peer Instruction?

口 I am satisfied with how I teach now

$\square$ I am not familiar with the logistics/resources needed

$\square$ There is not enough evidence that Peer Instruction works

口 Using Peer Instruction might negatively impact my ability to cover material

- My class enrollment is too large to use Peer Instruction in my course(s)

- My class enrollment is too small to use Peer Instruction in my course(s)

口 Using Peer Instruction might interfere with getting tenure or promotion

口 I have not had enough time to try Peer Instruction

$\checkmark$ I have not had access to the resources needed to try Peer Instruction

$\checkmark$ Peer Instruction might not work for the type of students I teach

$\square$ My students might not like it

口 My classroom's physical setup prevents me from trying it

$\checkmark$ A colleague or peer has discouraged me from trying it

$\square$ It would not be possible to try it because of how my department sets curriculum

$\square$ Peer Instruction is not a good fit for the course(s) I teach

$\square$ other (enter)

Q29. Which one of these items do you consider as the most significant reason not to use Peer Instruction?

o I am satisfied with how I teach now

- I am not familiar with the logistics/resources needed

o There is not enough evidence that Peer Instruction works

○ Using Peer Instruction might negatively impact my ability to cover material

- My class enrollment is too large to use Peer Instruction in my course(s)

- My class enrollment is too small to use Peer Instruction in my course(s)

○ Using Peer Instruction might interfere with getting tenure or promotion

- I have not had enough time to try Peer Instruction

o I have not had access to the resources needed to try Peer Instruction

○ Peer Instruction might not work for the type of students I teach

○ My students might not like it

- My classroom's physical setup prevents me from trying it

- A colleague or peer has discouraged me from trying it

o It would not be possible to try it because of how my department sets curriculum

- Peer Instruction is not a good fit for the course(s) I teach

o other (enter)

Q30. (enter) What is, or was, your impression of students' view of Peer Instruction?
Q31. (enter) Why do you encourage others to use Peer Instruction?

Q32. (enter) How do you encourage others to use Peer Instruction?

Q33. What caused you to stop using Peer Instruction?

口 My students did not learn using Peer Instruction

口 Using Peer Instruction negatively impacted my ability to cover material

$\square$ My class enrollment is too large to use Peer Instruction in my class(es)

- My class enrollment is too small to use Peer Instruction in my class(es)

$\checkmark$ Using Peer Instruction interferes with getting tenure or promotion

$\square$ I do not have the resources needed to continue using Peer Instruction

口 Peer Instruction does not work for the type of students I teach

$\square$ My students do not like it

口 My classroom's physical setup prevents me from using it

$\square$ A colleague or peer has discouraged me from using it

口 My department or administration discouraged me from using it

口 other (enter)

Q34. Where do you learn about pedagogic innovations (not just Peer Instruction)?

$\square$ colleagues

口 internet (e.g., blogs, industry articles, ...)

口 professional literature (e.g., ACM, IEEE, ASEE, ...)

$\checkmark$ conference presentations (e.g., ACM SIGCSE, ITiCSE, ICER, CCSC, ACE, Koli, ...)

$\square$ other (enter)

Q35. What rewards exist for adopting pedagogic innovations (not just Peer Instruction)?

$\square$ none

口 satisfaction

口 money

口 rank

$\square$ other (enter)

Q36. Thank you for your responses.

If you would like to know more about this project, please email djb@acm.org with subject PI PROJECT.

\section{REFERENCES}

[1] Orit Avidov-Ungar, Becky Leshem, Adva Margaliot, and Etty Grobgeld. 2018. Faculty Use of the Active Learning Classroom: Barriers and Facilitators. Fournal of Information Technology Education: Research 17 (2018), 485-504.

[2] Sara Brownell and Kimberly D. Tanner. 2012. Barriers to faculty pedagogical change: Lack of training, time, incentives, and...tensions with professional identity? CBE Life Sciences Education 11, 4 (2012), 339-346. https://doi.org/10.1187/ cbe.12-09-0163

[3] Paul Carter. 2012. An Experience Report: On the Use of Multimedia Preinstruction and Just-in-time Teaching in a CS1 Course. In Proceedings of the 43rd ACM Technical Symposium on Computer Science Education (SIGCSE '12). ACM, New York, NY, USA, 361-366. https://doi.org/10.1145/2157136.2157244

[4] J. D. Chase and Edward G. Okie. 2000. Combining Cooperative Learning and Peer Instruction in Introductory Computer Science. SIGCSE Bull. 32, 1 (March 2000), 372-376. https://doi.org/10.1145/331795.331888

[5] Catherine H Crouch and Eric Mazur. 2001. Peer instruction: Ten years of experience and results. American journal of physics 69, 9 (2001), 970-977. https://doi.org/10.1119/1.1374249

[6] Quintin Cutts, Sarah Esper, Marlena Fecho, Stephen R. Foster, and Beth Simon. 2012. The Abstraction Transition Taxonomy: Developing Desired Learning Outcomes Through the Lens of Situated Cognition. In Proceedings of the Ninth 
Annual International Conference on International Computing Education Research (ICER '12). ACM, New York, NY, USA, 63-70. https://doi.org/10.1145/2361276. 2361290

[7] Pranita Deshpande, Cynthia B Lee, and Irfan Ahmed. 2019. Evaluation of Peer Instruction for Cybersecurity Education. In Proceedings of the 50th ACM Technical Symposium on Computer Science Education (SIGCSE '19). ACM, New York, NY, USA, 720-725. https://doi.org/10.1145/3287324.3287403

[8] Jesse Eickholt. 2018. Barriers to Active Learning for Computer Science Faculty (submitted 7 Aug 2018). (08 2018). https://arxiv.org/abs/1808.02426

[9] Sarah Esper. 2014. A Discussion on Adopting Peer Instruction in a Course Focused on Risk Management. f. Comput. Sci. Coll. 29, 4 (April 2014), 175-182. http://dl.acm.org/citation.cfm?id=2591468.2591496

[10] Richard M. Felder and Rebecca Brent. 1996. Navigating the Bumpy Road to Student-Centered Instruction. College Teaching 44, 2 (1996), 43-47. https: //doi.org/10.1080/87567555.1996.9933425

[11] Davide Fossati and Mark Guzdial. 2011. The use of evidence in the change making process of computer science educators.. In SIGCSE. 685-690.

[12] Tyler Greer, Qiang Hao, Mengguo Jing, and Bradley Barnes. 2019. On the Effects of Active Learning Environments in Computing Education. In Proceedings of the 50th ACM Technical Symposium on Computer Science Education (SIGCSE '19). ACM, New York, NY, USA, 267-272. https://doi.org/10.1145/3287324.3287345

[13] Charles Henderson, Melissa Dancy, and Magdalena Niewiadomska-Bugaj. 2012 Use of research-based instructional strategies in introductory physics: Where do faculty leave the innovation-decision process? Phys. Rev. ST Phys. Educ. Res. 8 (Jul 2012), 020104. Issue 2. https://doi.org/10.1103/PhysRevSTPER.8.020104

[14] Christopher Lynnly Hovey, Lecia Barker, and Vaughan Nagy. 2019. Survey Results on Why CS Faculty Adopt New Teaching Practices. In Proceedings of the 50th ACM Technical Symposium on Computer Science Education (SIGCSE '19). ACM, New York, NY, USA, 483-489. https://doi.org/10.1145/3287324.3287420

[15] William Johnson, Irfan Ahmed, Vassil Roussev, and Cynthia B Lee. 2017. Peer Instruction for Digital Forensics. In $2017\{$ USENIX $\}$ Workshop on Advances in Security Education $(\{A S E\}$ 17). Vancouver, BC.

[16] William E Johnson, Allison Luzader, Irfan Ahmed, Vassil Roussev, Golden G Richard III, and Cynthia B Lee. 2016. Development of peer instruction questions for cybersecurity education. In $2016\{$ USENIX $\}$ Workshop on Advances in Security Education ( $\{A S E\}$ 16). \{USENIX\} Association, Austin, TX. https://www.usenix. org/conference/ase16/workshop-program/presentation/johnson

[17] Jack Kinne, Eric Misner, Adam S. Carter, and Sharon M. Tuttle. 2018. Evaluating the Efficacy of Clicker-based Peer Instruction Across Multiple Courses at a Single Institution. f. Comput. Sci. Coll. 34, 1 (Oct. 2018), 164-170. http://dl.acm.org/ citation.cfm?id=3280489.3280516

[18] B. Kitchenham and S Charters. 2007. Guidelines for performing Systematic Literature Reviews in Software Engineering.

[19] Nathaniel Lasry, Elizabeth Charles, Chris Whittaker, and Michael Lautman. 2009 When Talking Is Better Than Staying Quiet. AIP Conference Proceedings 1179, 1 (2009), 181-184. https://doi.org/10.1063/1.3266709

[20] Cynthia Bailey Lee. 2013. Experience Report: CS1 in MATLAB for Non-majors, with Media Computation and Peer Instruction. In Proceeding of the 44th ACM Technical Symposium on Computer Science Education (SIGCSE '13). ACM, New York, NY, USA, 35-40. https://doi.org/10.1145/2445196.2445214

[21] Vicki Lind. 2008. High Quality Professional Development: An Investigation of the Supports for and Barriers to Professional Development in Arts Education. International fournal of Education the Arts 8 (01 2008).

[22] Andrew Luxton-Reilly, Simon, Ibrahim Albluwi, Brett A. Becker, Michail Giannakos, Amruth N. Kumar, Linda Ott, James Paterson, Michael James Scott, Judy Sheard, and Claudia Szabo. 2018. Introductory Programming: A Systematic Literature Review. In Proceedings Companion of the 23rd Annual ACM Conference on Innovation and Technology in Computer Science Education (ITiCSE 2018 Companion). ACM, New York, NY, USA, 55-106. https://doi.org/10.1145/3293881.3295779

[23] Eric Mazur and Robert C Hilborn. 1997. Peer instruction: A user's manual. Vol. 5. Prentice Hall Upper Saddle River, NJ.

[24] R. P. Medeiros, G. L. Ramalho, and T. P. Falcão. 2019. A Systematic Literature Review on Teaching and Learning Introductory Programming in Higher Education. IEEE Transactions on Education 62, 2 (May 2019), 77-90. https //doi.org/10.1109/TE.2018.2864133

[25] Bin Peng. 2017. Experience Report: Peer Instruction in Java Programming Course in a Small Department. 7. Comput. Sci. Coll. 32, 5 (May 2017), 111-117. http //dl.acm.org/citation.cfm?id=3069621.3069648

[26] Leo Porter, Cynthia Bailey Lee, and Beth Simon. 2013. Halving Fail Rates Using Peer Instruction: A Study of Four Computer Science Courses. In Proceeding of the 44th ACM Technical Symposium on Computer Science Education (SIGCSE '13). ACM, New York, NY, USA, 177-182. https://doi.org/10.1145/2445196.2445250

[27] Leo Porter, Cynthia Bailey Lee, Beth Simon, Quintin Cutts, and Daniel Zingaro. 2011. Experience Report: A Multi-classroom Report on the Value of Peer Instruction. In Proceedings of the 16th Annual foint Conference on Innovation and Technology in Computer Science Education (ITiCSE '11). ACM, New York, NY, USA, 138-142. https://doi.org/10.1145/1999747.1999788
[28] Leo Porter, Cynthia Bailey Lee, Beth Simon, and Daniel Zingaro. 2011. Peer Instruction: Do Students Really Learn from Peer Discussion in Computing?. In Proceedings of the Seventh International Workshop on Computing Education Research (ICER '11). ACM, New York, NY, USA, 45-52. https://doi.org/10.1145/ 2016911.2016923

[29] Leo Porter, Dennis Bouvier, Quintin Cutts, Scott Grissom, Cynthia Lee, Robert McCartney, Daniel Zingaro, and Beth Simon. 2016. A Multi-institutional Study of Peer Instruction in Introductory Computing. In Proceedings of the 47th ACM Technical Symposium on Computing Science Education (SIGCSE '16). ACM, New York, NY, USA, 358-363. https://doi.org/10.1145/2839509.2844642

[30] Leo Porter, Dennis Bouvier, Quintin Cutts, Scott Grissom, Cynthia Lee, Robert McCartney, Daniel Zingaro, and Beth Simon. 2016. A Multi-institutional Study of Peer Instruction in Introductory Computing. ACM Inroads 7, 2 (May 2016), 76-81. https://doi.org/10.1145/2938142

[31] Leo Porter, Saturnino Garcia, John Glick, Andrew Matusiewicz, and Cynthia Taylor. 2013. Peer Instruction in Computer Science at Small Liberal Arts Colleges. In Proceedings of the 18th ACM Conference on Innovation and Technology in Computer Science Education (ITiCSE '13). ACM, New York, NY, USA, 129-134. https://doi.org/10.1145/2462476.2465587

[32] Leo Porter and Beth Simon. 2013. Retaining Nearly One-third More Majors with a Trio of Instructional Best Practices in CS1. In Proceeding of the 44th ACM Technical Symposium on Computer Science Education (SIGCSE '13). ACM, New York, NY, USA, 165-170. https://doi.org/10.1145/2445196.2445248

[33] Leo Porter and Daniel Zingaro. 2014. Importance of Early Performance in CS1: Two Conflicting Assessment Stories. In Proceedings of the 45th ACM Technical Symposium on Computer Science Education (SIGCSE '14). ACM, New York, NY, USA, 295-300. https://doi.org/10.1145/2538862.2538912

[34] Beth A. Quinn. 2018. EngageCSEdu: The Beautiful Noise of Peer Instruction: An Interview with Beth Simon. ACM Inroads 9, 2 (April 2018), 19-21. https: //doi.org/10.1145/3194243

[35] Everett M Rogers. 2010. Diffusion of innovations. Simon and Schuster.

[36] Zaynab Sabagh and Alenoush Saroyan. 2014. Professors' Perceived Barriers and Incentives for Teaching Improvement. International Education Research 2 (09 2014), 18-40. https://doi.org/10.12735/ier.v2i3p18

[37] Kate Sanders, Marzieh Ahmadzadeh, Tony Clear, Stephen H Edwards, Mikey Goldweber, Chris Johnson, Raymond Lister, Robert McCartney, Elizabeth Patitsas, and Jaime Spacco. 2013. The Canterbury QuestionBank: building a repository of multiple-choice CS1 and CS2 questions. In Proceedings of the ITiCSE working group reports conference on Innovation and technology in computer science educationworking group reports. ACM, 33-52.

[38] Beth Simon and Quintin Cutts. 2012. How to implement a peer instructiondesigned CS principles course. ACM Inroads 3, 2 (June 2012), 72-74. https: //doi.org/10.1145/2189835.2189858

[39] Beth Simon and Quintin Cutts. 2012. Peer Instruction: A Teaching Method to Foster Deep Understanding. Commun. ACM 55, 2 (Feb. 2012), 27-29. https: //doi.org/10.1145/2076450.2076459

[40] Beth Simon, Sarah Esper, Leo Porter, and Quintin Cutts. 2013. Student Experience in a Student-centered Peer Instruction Classroom. In Proceedings of the Ninth Annual International ACM Conference on International Computing Education Research (ICER '13). ACM, New York, NY, USA, 129-136. https: //doi.org/10.1145/2493394.2493407

[41] Beth Simon, Michael Kohanfars, Jeff Lee, Karen Tamayo, and Quintin Cutts. 2010. Experience Report: Peer Instruction in Introductory Computing. In Proceedings of the 41st ACM Technical Symposium on Computer Science Education (SIGCSE '10). ACM, New York, NY, USA, 341-345. https://doi.org/10.1145/1734263.1734381

[42] Beth Simon, Julian Parris, and Jaime Spacco. 2013. How We Teach Impacts Student Learning: Peer Instruction vs. Lecture in CS0. In Proceeding of the 44th ACM Technical Symposium on Computer Science Education (SIGCSE '13). ACM, New York, NY, USA, 41-46. https://doi.org/10.1145/2445196.2445215

[43] Dennis Sunal, Jeanelle Hodges, Cynthia Sunal, Kevin W. Whitaker, L Michael Freeman, Leo Edwards, Ronald A. Johnston, and Michael Odell. 2010. Teaching Science in Higher Education: Faculty Professional Development and Barriers to Change. School Science and Mathematics 101 (03 2010), 246-257. https: //doi.org/10.1111/j.1949-8594.2001.tb18027.x

[44] Chandra Turpen, Melissa Dancy, and Charles Henderson. 2010. Faculty perspectives on using peer instruction: A national study. In AIP conference proceedings, Vol. 1289. AIP, 325-328. https://doi.org/10.1063/1.3515235

[45] Chandra Turpen, Melissa Dancy, and Charles Henderson. 2016. Perceived affordances and constraints regarding instructors' use of Peer Instruction: Implications for promoting instructional change. Phys. Rev. Phys. Educ. Res. 12 (Feb 2016), 010116. Issue 1. https://doi.org/10.1103/PhysRevPhysEducRes.12.010116

[46] Trisha Vickrey, Kaitlyn Rosploch, Reihaneh Rahmanian, Matthew Pilarz, and Marilyne Nicole Olivia Stains. 2015. Research-Based Implementation of Peer Instruction: A Literature Review. In CBE life sciences education. https://doi.org/ 10.1187/cbe.14-11-0198

[47] Kevin C. Webb and Cynthia Taylor. 2014. Developing a Pre- and Post-course Concept Inventory to Gauge Operating Systems Learning. In Proceedings of the 45th ACM Technical Symposium on Computer Science Education (SIGCSE '14). 


\section{CompEd WG-3 Report}

ACM, New York, NY, USA, 103-108. https://doi.org/10.1145/2538862.2538886

[48] Daniel Zingaro. 2014. Peer Instruction Contributes to Self-efficacy in CS1. In Proceedings of the 45th ACM Technical Symposium on Computer Science Education (SIGCSE '14). ACM, New York, NY, USA, 373-378. https://doi.org/10.1145/ 2538862.2538878

[49] Daniel Zingaro and Leo Porter. 2014. Peer Instruction: A Link to the Exam. In Proceedings of the 2014 Conference on Innovation \& Technology in Computer Science Education (ITiCSE '14). ACM, New York, NY, USA, 255-260. https://doi.org/10. 1145/2591708.2591711

[50] Daniel Zingaro and Leo Porter. 2014. Peer Instruction in computing: The value of instructor intervention. Computers Education 71 (2014), 87-96. https://doi. org/10.1016/j.compedu.2013.09.015

[51] Daniel Zingaro, Leo Porter, Quintin Cutts, John Glick, Joe Hummel, Cynthia Lee, and Jaime Spacco. 2015. Supporting New Adopters to Peer Instruction in
CompEd-WGR'19, May 17-19, 2019, Chengdu, Sichuan, China

Computing. In Proceedings of the 46th ACM Technical Symposium on Computer Science Education (SIGCSE '15). ACM, New York, NY, USA, 710-710. https: //doi.org/10.1145/2676723.2678287

[52] Daniel Zingaro, Leo Porter, Quintin Cutts, John Glick, Joe Hummel, Cynthia Lee, and Jaime Spacco. 2016. Peer Instruction in Computing: A Focus on Student Learning. In Proceedings of the 47th ACM Technical Symposium on Computing Science Education (SIGCSE '16). ACM, New York, NY, USA, 714-714. https: //doi.org/10.1145/2839509.2844690

[53] Daniel Zingaro, Leo Porter, Beth Simon, and John Glick. 2011. Peer Instruction in the CS Classroom: A Hands-on Introduction: Conference Tutorial. 7. Comput. Sci. Coll. 26, 4 (April 2011), 218-218. http://dl.acm.org/citation.cfm?id=1953573. 1953609 